\title{
Space-based retrievals of air-sea gas transfer velocities using altimeters: Calibration for dimethyl sulfide
}

\author{
Lonneke Goddijn-Murphy, ${ }^{1}$ David K. Woolf, ${ }^{1}$ and Christa Marandino ${ }^{2}$
}

Received 22 August 2011; revised 11 June 2012; accepted 1 July 2012; published 24 August 2012.

[1] This study is the first to directly correlate gas transfer velocity, measured at sea using the eddy-correlation (EC) technique, and satellite altimeter backscattering. During eight research cruises in different parts of the world, gas transfer velocity of dimethyl sulfide (DMS) was measured. The sample times and locations were compared with overpass times and locations of remote sensing satellites carrying Ku-band altimeters: ERS-1, ERS-2, TOPEX, POSEIDON, GEOSAT Follow-On, JASON-1, JASON-2 and ENVISAT. The result was 179 pairs of gas transfer velocity measurements and backscattering coefficients. An inter-calibration of the different altimeters significantly reduced data scatter. The intercalibrated data was best fitted to a quadratic relation between the inverse of the backscattering coefficients and the gas transfer velocity measurements. A gas transfer parameterization based on backscattering, corresponding with sea surface roughness, might be expected to perform better than wind speed-based parameterizations. Our results, however, did not show improvement compared to direct correlation of shipboard wind speeds. The relationship of gas transfer velocity to satellite-derived backscatter, or wind speed, is useful to provide retrieval algorithms. Gas transfer velocity $(\mathrm{cm} / \mathrm{hr})$, corrected to a Schmidt number of 660 , is proportional to wind speed $(\mathrm{m} / \mathrm{s})$. The measured gas transfer velocity is controlled by both the individual water-side and air-side gas transfer velocities. We calculated the latter using a numerical scheme, to derive water-side gas transfer velocity. DMS is sufficiently soluble to neglect bubble-mediated gas transfer, thus, the DMS transfer velocities could be applied to estimate water-side gas transfer velocities through the unbroken surface of any other gas.

Citation: Goddijn-Murphy, L., D. K. Woolf, and C. Marandino (2012), Space-based retrievals of air-sea gas transfer velocities using altimeters: Calibration for dimethyl sulfide, J. Geophys. Res., 117, C08028, doi:10.1029/2011JC007535.

\section{Background}

\subsection{Introduction}

[2] Estimates of air-sea gas transfer velocity, derived from direct flux measurements, are poorly modeled by parameterizations based on wind speed and Schmidt number. This leads to large uncertainties in the calculation of global air-sea fluxes of climatically important gases, such as dimethyl sulfide $\left(\mathrm{CH}_{3}-\mathrm{S}-\mathrm{CH}_{3}\right.$ or DMS) and carbon dioxide $\left(\mathrm{CO}_{2}\right)$. For example, the computed total air-sea flux of $\mathrm{CO}_{2}$ can vary within a factor 3 by applying a range of common gas transfer parameterizations and wind speed data sources [Fangohr et al., 2008]. There are many different physical processes that may influence air-sea gas transfer, either directly or indirectly. A detailed overview of these processes

\footnotetext{
${ }^{1}$ Environmental Research Institute, UHI-NHC, Thurso, UK.

${ }^{2}$ IFM-GEOMAR, Kiel, Germany.

Corresponding author: L. Goddijn-Murphy, Environmental Research Institute, UHI-NHC, CfEE Building, Ormlie Road, Thurso KW14 7EE, UK. (lonneke.goddijn-murphy@uhi.ac.uk)

(C2012. American Geophysical Union. All Rights Reserved. 0148-0227/12/2011JC007535
}

and their interactions, given by Bock et al. [1999], illustrates that there are no direct effects of wind on the gas exchange. Wind may only have an indirect effect by generating wind waves, near surface turbulence, and bubbles, which influence gas exchange processes. In general, transfer can occur directly across the unbroken sea surface, or can be mediated by bubbles or particles. Direct gas transfer is dependent on the short gravity wave portion of the surface wave spectrum [Bock et al., 1999]. An alternative approach for assessing gas transfer, therefore, is to measure sea surface roughness, represented by the mean square slope, $\left\langle s^{2}\right\rangle$, of short capillarygravity waves.

[3] The considerations above underpin attempts to relate gas transfer velocity to a practical measurement of sea surface roughness. Both active and passive microwave signatures of the sea surface are sensitive to surface roughness, which suggest a range of satellite-based methods of estimating gas transfer velocity. Most interest has focused on satellite radar altimeters, because of the theoretical relationship of altimeter backscatter to sea surface roughness (i.e., radar scattering at nadir incidence), and the availability of long time series of satellite altimeter data. Two approaches, both based on implicit relationships between $\left\langle s^{2}\right\rangle$ and gas transfer velocity 
have been reported. (1) Glover et al. [2002] and Fangohr and Woolf [2007] applied linear relations for direct gas transfer, determined from wind-wave tank experiments [Bock et al., 1999]. The same linear relationships are not likely to hold for larger wind wave flumes, or in the open ocean, since under these conditions total $\left\langle s^{2}\right\rangle$ is significantly higher due to contributions from longer gravity waves [Bock et al., 1999]. (2) Frew et al. [2004] obtained field measurements of both $\left\langle s^{2}\right\rangle$ and heat transfer velocity in coastal and offshore waters. The heat transfer velocities are derived from infrared imagery, and extrapolated to gas transfer velocities assuming surface renewal. It is found that gas transfer velocity varies linearly with $\left\langle s^{2}\right\rangle$ over wave numbers between 40 and $800 \mathrm{rad} / \mathrm{m}$, and varies linearly with the square of $\left\langle s^{2}\right\rangle$ over wave numbers between 40 and $100 \mathrm{rad} / \mathrm{m}$. Although this method produces reasonable results, it is controversial and needs to be confirmed with direct gas flux measurements [Frew et al., 2007]. In these two approaches, the mean square slope of the sea surface, $\left\langle s^{2}\right\rangle$, is then derived from satellitebased altimeter observations.

[4] Altimeters measure microwave backscatter, and for nadir looking active microwave sensors, the reflected power is inversely related to $\left\langle s^{2}\right\rangle$ [Chapron et al., 1995]. The contribution of longer waves to the observed $\left\langle s^{2}\right\rangle$ can be removed by using dual-frequency altimeters, and subtracting the estimate of $\left\langle s^{2}\right\rangle$ from the C-band $(5.3 \mathrm{GHz}, 40 \mathrm{rad} / \mathrm{m}, 5.5 \mathrm{~cm})$ from the estimate of $\left\langle s^{2}\right\rangle$ from the Ku-band $(13.6 \mathrm{GHz}, 100 \mathrm{rad} / \mathrm{m}$, $2.1 \mathrm{~cm}$ ) [Frew et al., 2007, 2004; Glover et al., 2007, 2002]. Using single $\mathrm{Ku}$-band scattering has also given satisfactory results [Fangohr and Woolf, 2007]. This simplification is supported by the observation that in the absence of largescale wave breaking gas transfer velocity has been found to correlate slightly better with total $\left\langle s^{2}\right\rangle$, than with the $\left\langle s^{2}\right\rangle$ of short wind waves only [Jähne et al., 1987; Bock et al., 1999]. However, the better correlation to total slope is not understood since the longer waves are not directly involved in the air-sea exchange process.

[5] Here, we will take a more direct, pragmatic and statistical approach; by seeking a direct relationship between altimeter backscatter and transfer velocity. This study is the first to directly correlate altimeter backscatter and field measurements of gas transfer velocity. Open ocean gas transfer velocity measurements of DMS, derived using the eddy-correlation (EC) technique are used with coincident Ku-band scattering data from a range of altimeters. As explained in the next section, bubble-mediated gas transfer is presumed negligible for DMS, therefore all gas transfer is through the unbroken surface. Using gas transfer velocity measurements of DMS instead of $\mathrm{CO}_{2}$ has a number of advantages. DMS is produced in ocean surfaces around the globe and the air-sea gradient is always from the ocean to the atmosphere. Also, DMS air-sea concentration difference is large relative to the atmospheric background concentration due to the short atmospheric lifetime of DMS. Atmospheric DMS varies by tens of percent, while $\mathrm{CO}_{2}$ fluctuations are only a fraction of a percent of the air concentration [Huebert et al., 2004]. As a consequence, while a sampling time of DMS fluxes of one hour achieves a 15-20\% uncertainty due to sampling error on the mean estimate, for $\mathrm{CO}_{2}$ fluxes the sampling errors are of a much higher order [Huebert et al., 2004]. DMS in the open ocean is derived exclusively from phytoplankton, and the lack of other sources makes DMS an ideal gas with which to study air-sea exchange [Yang et al., 2009]. DMS is an important gas in climate studies, as it may be a precursor of atmospheric sulfate particles upon which cloud droplet forms. The transfer velocities of DMS can also be used by analogy to derive remote sensing algorithms for many other gases, including the greenhouse gases $\mathrm{CO}_{2}$, and methane $\left(\mathrm{CH}_{4}\right)$. However, before DMS can be used to derive the algorithms for other gases, it is necessary to understand how the diffusivity (expressed by Schmidt number) and solubility of a gas can affect transfer across the sea surface. This is explained in the following section 1.2.

\subsection{Gas Transfer Processes}

[6] Gas transfer across the sea surface involves many processes, and observed $K_{\mathrm{w}}(\mathrm{cm} / \mathrm{hr})$ represents the overall transfer velocity. Total gas transfer can be described by,

$$
F=K_{w}\left(C_{a} / H-C_{w}\right)
$$

[Liss and Merlivat, 1986], where $F$ is the gas flux, and $C_{\mathrm{a}}$ and $C_{\mathrm{w}}$ are the respective concentrations of the gas in the bulk air and bulk water. $F$ is positive for a gas flux from the atmosphere to the ocean by our convention. $H$ is the dimensionless gasover-liquid form of the Henry's law constant (or more correctly 'coefficient' as this term varies with temperature and to a lesser extent with salinity), expressed by

$$
H=\frac{C_{a i}}{C_{w i}}
$$

where $C_{\mathrm{ai}}$ and $C_{\mathrm{wi}}$ represent the concentrations of the air and seawater sides of the interface. $K_{\mathrm{w}}$ is dependent on the individual transfer velocities in water, $k_{\mathrm{w}}$, and in air, $k_{\mathrm{a}}$. It can be shown that for chemically unreactive gases,

$$
\frac{1}{K_{w}}=\frac{1}{k_{w}}+\frac{1}{H k_{a}}
$$

[Liss and Merlivat, 1986]. Air-sea gas transfer parameterizations are mostly concerned with water-side gas transfer velocity, $k_{\mathrm{w}}$. A largely separate literature is concerned with parameterization of the air-side transfer velocity, $k_{\mathrm{a}}$ [Johnson, 2010]. Woolf [2005] proposes a hybrid model, in which $k_{\mathrm{w}}$ is a simple sum of the water-side gas transfer velocities through the unbroken sea surface, $k_{\mathrm{w}, 0}$, and through bubbles, $k_{\mathrm{w}, \mathrm{b}}$. The term $k_{\mathrm{w}, \mathrm{b}}$ may have to be included for insoluble gases such as $\mathrm{CO}_{2}, \mathrm{CH}_{4}$ and oxygen $\left(\mathrm{O}_{2}\right)$, but for relatively soluble gases, such as DMS, this term is thought to be insignificant [Woolf, 1993, 1997]. In practice, for insoluble gases $C_{\mathrm{ai}} \gg$ $C_{\text {wi }}$, and the rate limiting step is transfer through the water side. In these cases, the term $1 / k_{\mathrm{w}}$ dominates (3), and $k_{\mathrm{w}}$ is often taken as an adequate estimation of $K_{\mathrm{w}}$, simplifying (1) to $F=k_{\mathrm{w}}\left(C_{\mathrm{a}} / H-C_{\mathrm{w}}\right)$. DMS is a more soluble gas, however; according to Blomquist et al. [2006] the ratio of air side resistance to water side resistance for DMS is about 0.05 versus 0.005 for $\mathrm{CO}_{2}$ because of increased solubility. Laboratory experiments with DMS suggest that at low temperatures or moderate wind speeds both $k_{\mathrm{a}}$ and $k_{\mathrm{w}}$ may have to be included in air-sea flux estimates [McGillis et al., 2000]. Their prediction for an ocean environment, based on known parameterizations of $k_{\mathrm{w}}$ and $k_{\mathrm{a}}$, shows an underestimation of $k_{\mathrm{w}}$ by measurements of $K_{\mathrm{w}}$, that increases with increasing wind speed as well as with decreasing temperature. For our survey conditions, their 
Table 1. Different Gas Transfer Velocity Coefficients $(\mathrm{cm} / \mathrm{hr})$, as Used in the Text

\begin{tabular}{lllll}
\hline & \multicolumn{1}{c}{ Description } & \multicolumn{1}{c}{ DMS } & \multicolumn{1}{c}{ Insoluble Gas } & \multicolumn{1}{c}{ Any Gas } \\
\hline$K_{\mathrm{w}}$ & Total & Equation $(3)$ & $K_{\mathrm{w}}=k_{\mathrm{w}}$ & Equation (3) \\
$k_{\mathrm{w}}$ & Water-side & $k_{\mathrm{w}} \approx k_{\mathrm{w}, 0}$ & $k_{\mathrm{w}}=k_{\mathrm{w}, 0}+k_{\mathrm{w}, \mathrm{b}}$ & $k_{\mathrm{w}}=k_{\mathrm{w}, 0}+k_{\mathrm{w}, \mathrm{b}}$ \\
$k_{\mathrm{w}, \mathrm{b}}$ & Bubble-mediated & $k_{\mathrm{w}, \mathrm{b}} \approx 0$ & nonzero & Solubility dependent \\
$k_{\mathrm{w}, 0}$ & Direct & $k_{\mathrm{w}, 0} \approx k_{\mathrm{w}}$ & $k_{\mathrm{w}, 0}=k_{\mathrm{w}}-k_{\mathrm{w}, \mathrm{b}}$ & $k_{\mathrm{w}, 0}=k_{\mathrm{w}}-k_{\mathrm{w}, \mathrm{b}}$ \\
$k_{\mathrm{a}}$ & Air-side & Equation $(5)$ & $-\overline{\mathrm{a}}$ & Equation $(5)$ \\
$K_{\mathrm{w}, 660}$ & $K_{\mathrm{w}, 660}=K_{\mathrm{w}}(\mathrm{Sc} / 660)^{1 / 2}$ & $-\mathrm{b}$ & $K_{\mathrm{w}, 660}=k_{\mathrm{w}, 660}$ & NA \\
$k_{\mathrm{w}, 660}$ & $k_{\mathrm{w}, 660}=k_{\mathrm{w}}(\mathrm{Sc} / 660)^{1 / 2}$ & Equation $(6)$ & $k_{\mathrm{w}, 660}=K_{\mathrm{w}, 660}$ & $k_{\mathrm{w}, 660}=k_{\mathrm{w}}(\mathrm{Sc} / 660)^{1 / 2}$ \\
\hline
\end{tabular}

${ }^{\mathrm{a}} k_{\mathrm{a}}$ can be determined by equation (5), but this is unnecessary since $H k_{\mathrm{a}} / K_{\mathrm{w}} \rightarrow \infty$.

${ }^{\mathrm{b}} \mathrm{S}$ chmidt number scaling applies to water-side (and not total) gas transfer, however, the $K_{\mathrm{w}}$ measurements in our study were multiplied by $(\mathrm{Sc} / 660)^{1 / 2}$ to define $K_{\mathrm{w}, 660}$.

expected error could be up to $20 \%$. We verified this prediction by calculating temperature and salinity dependent values of $H$ and $k_{\mathrm{a}}$ for DMS using Johnson [2010]'s numerical scheme. First, we interpolated the Ostwald solubility coefficient $(L)$ in distilled water as a function of temperature $T(\mathrm{~K})$ as presented by Dacey et al. [1984] and found $\ln (L)=3787 / T(\mathrm{~K})-10.27$. Dimensionless $H$ (2) is the inverse of $L$, in pure water denoted by $H_{0}$. For a given salinity $(S) H$ was then computed with:

$$
H=H_{0} \times 10^{K_{S} S}
$$

where $K_{\mathrm{S}}$ is the empirical Setschenow constant [Johnson, 2010]. The derivation of $K_{\mathrm{S}}$ is detailed by Johnson [2010]; for DMS we found $K_{\mathrm{S}}=2.76 \times 10^{-3}$. Air side gas transfer velocity was modeled using:

$$
k_{a}=1 \times 10^{-3}+\frac{u *}{13.3 S c_{a}^{1 / 2}+C_{D}^{-1 / 2}-5+\ln \left(S c_{a}\right) / 2 \kappa}
$$

[Johnson, 2010], an improvement on previous $k_{\mathrm{a}}$ models because it accounts for the apparent nonlinear relationship with wind and the purely diffusive transfer at zero wind speed. Following Johnson [2010], friction velocity, $u_{*}$, was approximated from wind speed at $10 \mathrm{~m}$ height, $U_{10}(\mathrm{~m} / \mathrm{s})$, using $u_{*}=$ $U_{10}\left(6.1 \times 10^{-4}+6.3 \times 10^{-5} U_{10}\right)^{1 / 2}$. The drag coefficient, $C_{\mathrm{D}}$, was calculated with $C_{\mathrm{D}}=\left(0.61+0.063 U_{10}\right) \times 10^{-3}$, while the von Karman constant, $\kappa$, was taken to be 0.4 . The computation of the air temperature, $T_{\text {air }}$, dependent Schmidt number in air, $\mathrm{Sc}_{\mathrm{a}}$, is explained by Johnson [2010], and executed in section 3.3. Finally, $k_{\mathrm{w}}$ was derived from (3)-(5), and normalized to $\mathrm{Sc}=660$ using $k_{660} / k=(\mathrm{Sc} / 660)^{1 / 2}$; applying $k_{\mathrm{w}} \approx k_{\mathrm{w}, 0}$ for DMS resulted in:

$$
k_{w, 660}=\frac{H k_{a} K_{w, 660}}{H k_{a}-K_{w, 660}(S c / 660)^{-1 / 2}}
$$

The computed $k_{\mathrm{w}, 660}$ values were compared with the $K_{\mathrm{w}, 660}$ measurements to assess the significance of air-side control of the gas flux.

[7] Another important reason to separate the air-side and water-side coefficients is that if any extrapolation to other gases is undertaken, then it is important to apply specific models for exchange mechanisms on the appropriate side of the interface. Here, we have assumed an existing model for the air-side processes [Johnson, 2010], but we are free to interpret the calculated water-side coefficients. Two very different approaches can be considered. The first approach is simply to assume that the water-side transfer velocity for all gases is proportional to $\mathrm{Sc}^{-1 / 2}$. The second (and our recommended) approach is to assume that:

[8] 1. Water-side transfer velocities generally consist of additive contributions from direct and bubble-mediated transfer velocity;

[9] 2. DMS is sufficiently soluble that the contribution of bubble-mediated processes is negligible, and therefore the values of $k_{\mathrm{w}, 660}$ calculated for DMS using (6) can be considered to be a reasonable estimate of the direct contribution for a gas of Schmidt number 660;

[10] 3. The direct contribution to water-side transfer velocity, for any gas of arbitrary Schmidt number, can be calculated from $k_{\mathrm{w}, 660}$ assuming proportionality to $\mathrm{Sc}^{-1 / 2}$.

[11] Thus, DMS transfer velocities could be used to estimate gas transfer through the unbroken surface of any other gas. The calculation of the total water-side transfer velocity of a gas further requires a model of the bubble-mediated transfer velocity [e.g., Woolf, 1993, 1997]. An overview of the different definitions of gas transfer velocity is given in Table 1 . Note that we recommend neglecting the bubblemediated transfer of DMS and assuming $k_{\mathrm{w}} \alpha \mathrm{Sc}^{-1 / 2}$ as pragmatic steps. For more exact formulae, we refer the reader to Fairall et al. [2011].

\section{Methodology}

\subsection{Field Data}

[12] During eight cruises, shown in Figure 1, estimates of DMS transfer velocity, $K_{\mathrm{w}}(\mathrm{cm} / \mathrm{hr})$, were obtained from underway gas flux measurements using EC. The PHASE1, Knorr_06 and Knorr_07 cruises were performed by the University of California, Irvine, (UCI), while the University of Hawaii (UH) carried out the cruises TAO, BIO, DOGEE, SO-GasEx and VOCALS-Rex. The UH data has been made available online at $\mathrm{ftp}$ site $\mathrm{ftp}$ ://ftp.soest.hawaii.edu/showell/ outgoing/. The cruises comprised 3767 stations in total, of which gas transfer velocity measurements were available from 1347 stations. $K_{\mathrm{w}}$ was derived experimentally by dividing measured $F$ by the observed air-water concentration difference. The EC method is based on $F$ being proportional to the covariance between fluctuations in vertical wind velocity and simultaneously measured fluctuations in the concentrations of the gas of interest $\left(F=\rho_{\mathrm{a}}\left\langle w^{\prime} c^{\prime}\right\rangle\right.$ where $\rho_{\mathrm{a}}$ is the density of dry air). This technique is considered one of the most direct ways to determine the gas flux, because it does not rely on assumptions about gas properties or approximations concerning the turbulent structure of the atmospheric boundary layer. However, it is one of the more 


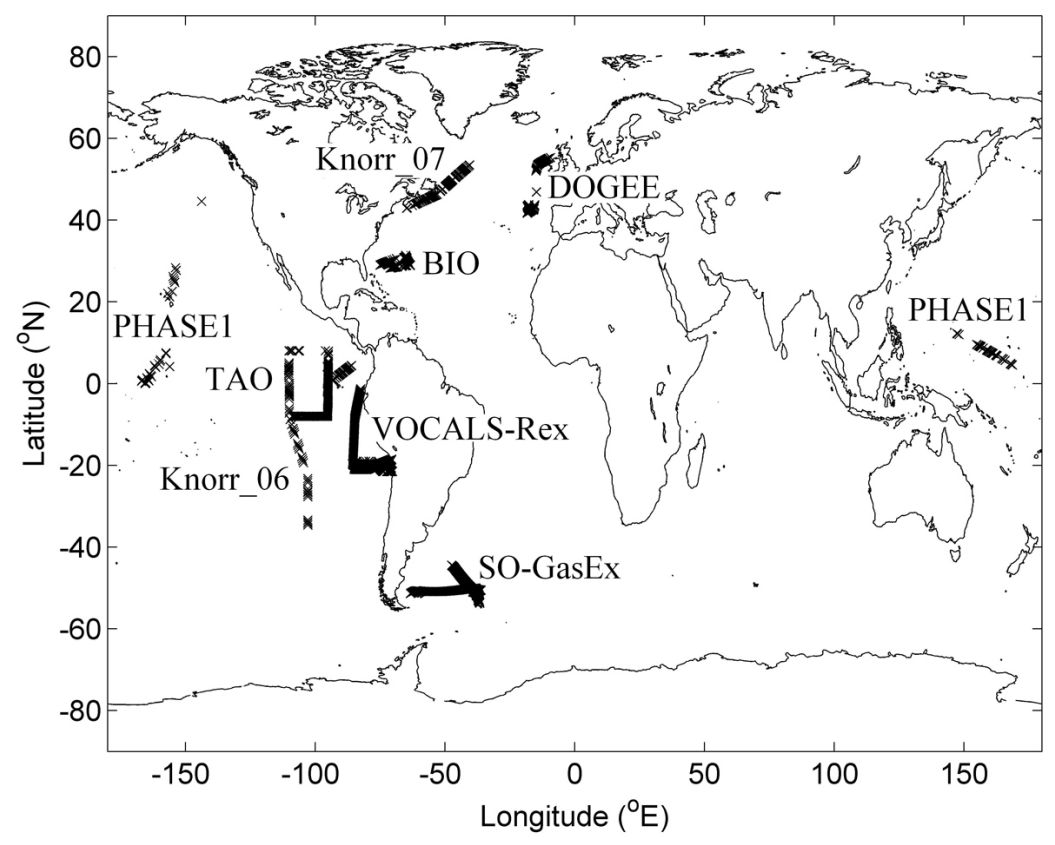

Figure 1. Stations of the cruises that provided DMS gas transfer velocity measurements, marked in crosses. TAO (Tropical Atmosphere Ocean) in 2003 in the Eastern Equatorial Pacific on the R/V Ronald H. Brown [Huebert et al., 2004]; BIO (Biocomplexity) in 2004 in the Sargasso Sea on the R/V Steward Johnson [Blomquist et al., 2006]; PHASE1 (Project Halogen Air Sea Exchange) in 2004 in Northern and Equatorial Pacific on the R/V Wecoma [Marandino et al., 2007]; Knorr 06 in 2006 in the Southeastern Pacific on R/V Knorr [Marandino et al., 2009]; Knorr 07 in 2007 in the Northern Atlantic on R/V Knorr [Marandino et al., 2008]; DOGEE (Deep Ocean Gas Exchange Experiment) in 2007 in the North East Atlantic on the RRS Discovery [Huebert et al., 2010]; SO-GasEx (Southern Ocean Gas Exchange Experiment) in 2008 in the Southern Ocean on the R/V Ronald H. Brown [Yang et al., 2011]; VOCALS-Rex (Vamos Ocean-Cloud-Atmosphere-Land Study Regional Experiment) in 2008 in Southeast Pacific on R/V Ronald H. Brown [Yang et al., 2009]; Data of TAO, BIO, DOGEE, SO-GasEx and VOCALS-Rex has been made available online at ftp site ftp://ftp.soest.hawaii.edu/showell/outgoing/.

challenging flux measurements to make in the field owing to small signal-to-noise ratios, which result from a very small signal and non-ideal measurement conditions found at sea [Wanninkhof et al., 2009]. A discussion of others pros and cons of the EC technique and a comparison with different air-sea gas flux measurement techniques can be found in Wanninkhof et al. [2009] and Nightingale [2009]. The measurements were averaged over $1 \mathrm{~h}$ time periods, except for the Knorr_07 cruise, when 20 min intervals were used. The UCI made corrections for the loss of high-frequency fluctuations, caused by the long length of tubing used to sample air from the bow. The high-frequency correction increases the fluxes, with a mean correction of $28 \%$ [Marandino et al., 2007]. The applied technique achieves a $K_{\mathrm{w}}$ uncertainty from about $15-20 \%$ [Huebert et al., 2004] to 25\% [Yang et al., 2009; Marandino et al., 2007, 2009]. All $K_{\mathrm{w}}$ measurements were normalized to $K_{\mathrm{w}}, 660$, by multiplying $K_{\mathrm{w}}$ with $(660 / \mathrm{Sc})^{-1 / 2}$, where $\mathrm{Sc}$ is the Schmidt number of the ambient DMS (576 to 2361). A range of other measured parameters were available, and we used $U_{10}, \mathrm{Sc}$, SST $\left({ }^{\circ} \mathrm{C}\right), T_{\text {air }}\left({ }^{\circ} \mathrm{C}\right)$, and $S(\%)$ to compute $H, \mathrm{Sc}_{\mathrm{a}}, k_{\mathrm{a}}$, and $k_{\mathrm{w}, 660}$.

[13] Measuring wind on a moving platform can be challenging. During all cruises, the ship's motion was measured and removed from apparent winds to get true winds. Data that were believed to be affected by flow distortion, relative wind directions greater than 60 degrees from either side of the bow (UH and UCI) or gyro heading varying by more than 30 degrees (UH), were filtered out. The UH wind speeds at a height of $10 \mathrm{~m}$ were normalized to neutral atmospheric stability using COARE 3.0 bulk flux model [Fairall et al., 2003]. The UCI wind speed measurements, taken at $10 \mathrm{~m}$ height (PHASE1 and Knorr_07) and at $7 \mathrm{~m}$ (Knorr_06), were not normalized. The wind speeds were averaged over the same intervals as the gas flux measurements, with sampling rates of $20 \mathrm{~Hz}(\mathrm{UH})$ and $50 \mathrm{~Hz}$ (UCI). For the UCI data the standard deviation of individual wind speed measurements about the hourly mean was $\sim 1 \mathrm{~m} / \mathrm{s}$ (15\%) typically. The measured wind speed ranged between 2.3 and $15.4 \mathrm{~m} / \mathrm{s}$.

[14] The different surveys were located in separate waters with SST ranging from $2^{\circ}$ to $30^{\circ} \mathrm{C}$ (Table 2). During the DOGEE cruise, surfactant patches were intentionally made in order to study their effect on gas transfer. The results from those experiments were excluded to avoid biasing this study. Marandino et al. [2009] found some indication of an SST trend, i.e., higher gas transfer coefficients with higher temperatures, looking at the TAO, BIO, PHASE1, and 
Table 2. Measurements at the Stations That Coincided With Altimeter Overpass Times and Locations ${ }^{\mathrm{a}}$

\begin{tabular}{|c|c|c|c|c|c|c|c|c|}
\hline \multirow[b]{2}{*}{ Cruise } & \multirow[b]{2}{*}{$N$} & \multicolumn{2}{|c|}{$\begin{array}{l}\mathrm{SST} \\
\left({ }^{\circ} \mathrm{C}\right)\end{array}$} & \multicolumn{4}{|c|}{$\begin{aligned} U_{10, \mathrm{a}}= & a U_{10, \text { is }}+b \\
& (\mathrm{~m} / \mathrm{s})\end{aligned}$} & \multirow{2}{*}{$\begin{array}{c}\begin{array}{c}U_{10, \mathrm{a}}=U_{10, \text { is }} \\
(\mathrm{m} / \mathrm{s})\end{array} \\
\text { RMSE }\end{array}$} \\
\hline & & Min & $\operatorname{Max}$ & $a$ & $b$ & $R^{2}$ & RMSE & \\
\hline TAO & 41 & 22.6 & 27.9 & 0.91 & 0.9 & 0.63 & 0.95 & 0.97 \\
\hline $\mathrm{BIO}$ & 53 & 27.4 & 28.9 & 0.75 & 1.5 & 0.58 & 1.0 & 1.1 \\
\hline PHASE I & 10 & 23.9 & 29.7 & NA & NA & $\sim 0$ & NA & NA \\
\hline Knorr_06 & 2 & 24.7 & 24.8 & NA & NA & NA & NA & NA \\
\hline Knorr_07 & 16 & 8.9 & 17.1 & 0.93 & 0.19 & 0.74 & 1.8 & 1.7 \\
\hline DOGEE & 6 & 16.8 & 18.6 & 0.90 & 0.21 & 0.85 & 0.84 & 0.81 \\
\hline SO-GasEx & 21 & 4.7 & 6 & 0.80 & 2.2 & 0.66 & 2.4 & 2.4 \\
\hline $\begin{array}{l}\text { VOCALS- } \\
\text { Rex }\end{array}$ & 30 & 17.1 & 24.5 & 0.90 & 1.5 & 0.62 & 0.72 & 1.2 \\
\hline All & 179 & 4.7 & 29.7 & 0.85 & 1.3 & 0.72 & 1.3 & 1.4 \\
\hline
\end{tabular}

${ }^{\mathrm{a}} N$, number of matching data points, $U_{10, a}$, corrected altimeter wind

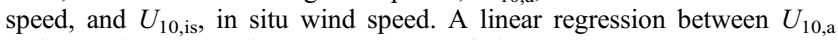
and $U_{10, \text { is }}$ is compared to a one-on-one relation.

Knorr_06 data. Another known feature of the data is that during the day, photochemical destruction may remove DMS from the surface layer. Yang et al. [2009] found during VOCALS-Rex a clearly visible sinusoidal diurnal cycle in DMS concentration on a number of days, even with the ship steaming at up to 12 knots. Diurnal patterns in DMS fluxes were not identified during TAO [Huebert et al., 2004] and Knorr 06 and PHASE1 [Marandino et al., 2009]. This could be explained by diurnal changes in DMS being minor compared to other varying environmental conditions and horizontal patchiness of DMS.

\subsection{Altimeter Data}

[15] The radar altimeter emits a radar wave, and the return signal reflected by a surface is analyzed. Satellite radar altimeters for ocean observations were primarily developed to measure sea-surface elevation, from which phenomena such as the large scale ocean circulation can be studied. In addition, significant wave height (SWH) and surface wind speed can be derived. Nadir looking altimeters fundamentally measure small scale surface roughness. Surface roughness causes incident microwaves to diffuse and scatter away from the altimeter's view, so that for rougher surfaces less backscattering is returned. Sea surface slopes are calculated from the normalized backscattering cross section, $\sigma$, by applying a geometrical optics (GO) model [Cox and Munk, 1954] to the scattering [Brown, 1979]. For normal incidence, $\sigma$ should be inversely proportional to $\left\langle s^{2}\right\rangle$. According to GO theory, microwaves are not scattered by wave facets smaller than about three times the incident wavelength, $\lambda_{\mathrm{i}}$. For $\mathrm{Ku}$-band scattering, $\sigma_{\mathrm{Ku}}, \lambda_{\mathrm{i}}=2.1 \mathrm{~cm}$, and hence only surface waves longer than $\lambda_{\text {cutoff }}=6.3 \mathrm{~cm}$ add to $\left\langle s^{2}\right\rangle$. According to a physical optics (PO) model, however, surface ripples on a smaller scale than $\lambda_{\text {cutoff }}$ contribute to attenuation of $\sigma_{\mathrm{Ku}}$ also [Chapron et al., 1995]. Employing known relationships between $U_{10}$ and $\left\langle s^{2}\right\rangle$, the PO model shows quite good agreement with the empirical Modified Chelton and Wentz (MCW) operational wind speed algorithm for the Ku-band altimeter [Chapron et al., 1995]. The MCW model was developed by Witter and Chelton [1991] for the GEOSAT altimeter, based on a cross calibration with the Seasat altimeter and using global wind statistics. The MCW algorithm, which has the form of a look up table, is still widely used in the operational retrieval of wind speed from Ku-band altimeters, such as those carried by ERS-1 and ERS-2 [Abdalla, 2007]. For the ENVISAT altimeter, Abdalla [2007] fine-tuned MCW, using buoy wind speeds and model wind speeds from the ECMWF (European Centre for Medium-Range Weather Forecasts). The resulting algorithm, now in use for ENVISAT, was extensively verified for the Ku-band altimeters of ENVISAT, ERS-2 and Jason-1 against ECMWF model and buoy observations. It performs better in terms of wind speed retrieval than the two-parameter algorithm ( $\sigma$ and wave height), developed by Gourrion et al. [2002] for TOPEX/ POSEIDON and implemented on JASON-1 [Abdalla, 2007].

[16] Altimeters on board the satellites ERS-1, ERS-2, TOPEX, POSEIDON, GEOSAT Follow-On, JASON-1, JASON-2 and ENVISAT have been measuring Ku-band backscatter from the ocean surface for 20 years. The C-band backscatter coefficient is also available for TOPEX, Jason$1 \& 2$, and the S-band backscatter coefficient is available for ENVISAT. As described above, different calibrations and algorithms have been in operation for the different altimeters. In addition, electronic drifts and sensor degradations can affect the quality of the data on the long-term, inducing discrepancies between the various satellites. Data processing using a method based on buoy and cross-satellite comparisons, as described by Queffeulou and collaborators [Abdalla, 2007; Queffeulou, 2004; Queffeulou et al., 2010], has produced the homogeneous and calibrated data set released in May 2010 from the IFREMER laboratoire d'océanographie spatiale (ftp://ftp.ifremer.fr/ifremer/cersat/ products/swath/altimeters/waves/data/). This database contains long-term records in a consistent format of $\sigma_{\mathrm{Ku}}(\mathrm{dB})$ (calibrated and non-calibrated), SWH (m) (1 s average, standard deviation, and corrected), and $U_{10}(\mathrm{~m} / \mathrm{s})$ (uncorrected and corrected). At present, data are available from 1 August 1991 to 3 March 2010, but the database has the potential to be updated indefinitely. The corrections to the altimeter SWH measurements are presented by Queffeulou [2004]. The more complex $\sigma_{\mathrm{Ku}}$ calibration is computed in three steps [Queffeulou et al., 2010]. First, the $\sigma_{\mathrm{Ku}}$ measurements are calibrated according to information obtained from the supplying agencies. Next, the $\sigma_{\mathrm{Ku}}$ data are inter-calibrated using long-term comparisons of monthly mean estimates of the different altimeters on a global scale. Because the ENVISAT monthly mean value of $\sigma_{\mathrm{Ku}}$ appears to be the most stable with time, all $\sigma_{\mathrm{Ku}}$ measurements are adjusted to those of ENVISAT. The adjustment is done over a common period between ENVISAT and each altimeter. For ERS-1 the correction is relative to ERS-2 measurements, while ERS-2 itself is adjusted to ENVISAT. In a final step, the altimeter wind speed algorithm of Abdalla [2007] is applied, to tune $\sigma_{\mathrm{Ku}}$ to a best fit between altimeter and buoy collocated $U_{10}$ data. All calibration and correction methods are expected to improve with time. For this study, we used the update of May 2010, this version is called wave merge 7.0 in the documentation sub-folder of the aforementioned IFREMER ftp site.

[17] The technology of the satellites progressed during the years. For example, Jason-1 upgraded from retracker MLE-3 to MLE-4 in 21 October 2005 (http://www.aviso.oceanobs. 
(a)

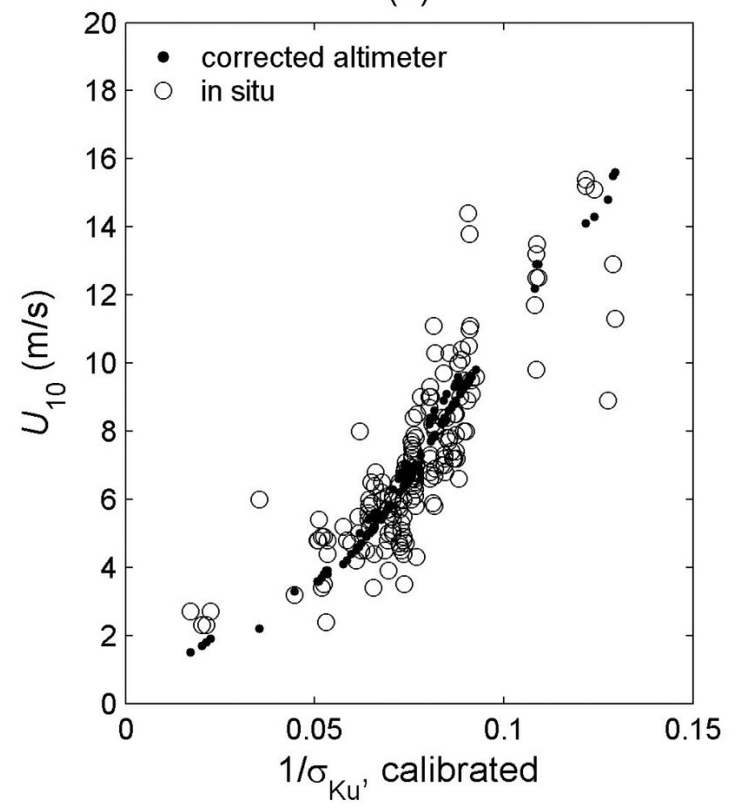

(b)

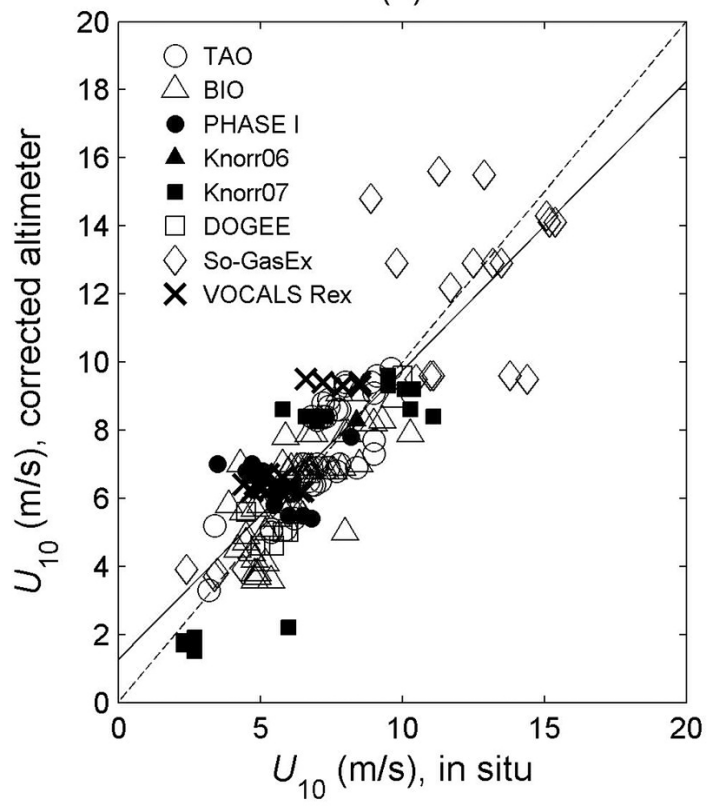

Figure 2. Scatterplots of in situ $U_{10}$ combined with coinciding altimeter data. (a) $U_{10}$ against $1 / \sigma_{\mathrm{Ku}}$ from calibrated altimeter $\sigma_{\mathrm{Ku}}$ (linear); black dots indicate corrected altimeter $\mathrm{U}_{10}$, and open circles in situ $\mathrm{U}_{10}$. (b) Corrected altimeter $\mathrm{U}_{10}$ against in situ $\mathrm{U}_{10}$; solid line shows a linear $\mathrm{y}$-on-x regression, $\mathrm{y}=0.85 \mathrm{x}+$ $1.25\left(\mathrm{R}^{2}=0.72, \mathrm{RMSE}=1.3\right)$, and dashed line a one-on-one relation $(\mathrm{RMSE}=1.4)$.

com/en/data/product-information/monomission-data-updates/ index.html). (Its successor Jason-2 used MLE-4 from the start in June 2008.) It is understood that adjustments that improve altimeter wind speed and sea surface height estimates on shorter scales, as does using the MLE-4 instead of the MLE-3 retracker, will have minimal impact on altimeter data validated over global scales $(>50 \mathrm{~km})$ [Quartly, 2009]. Because the inter-calibration of the altimeters by Queffeulou was based on monthly global wind statistics and buoy and ECMWF model wind data, information of the individual altimeters on more subtle geo-physical retrievals such as air-sea gas transfer that would benefit from the MLE-4 retracker was possibly lost during the inter-calibration process. However, maybe not all benefits were removed by the inter-calibration and applying MLE-4 could improve the correlation between backscatter and gas transfer velocity by some amount. We tested this possibility (section 3.2).

[18] For the eight cruises, we downloaded daily altimeter data files corresponding with the survey days, and compared times and locations of each station with altimeters overpass times and locations. We searched for altimeter data points within $6 \mathrm{~h}$ time difference and $0.5^{\circ}$ great circle distance, and averaged the altimeter data over these points (the consequences of these criteria are discussed in the following section 3.1). The result was 179 matches between in situ and altimeter derived measurements, 151 for the $\mathrm{UH}$ and 28 for the UCI data (Figure 1 and Table 2). We used the corrected values of the altimeter $U_{10}$. Because $\sigma_{\mathrm{Ku}}$ is proportional to $1 /\left\langle s^{2}\right\rangle$ rather than $\log \left(1 /\left\langle s^{2}\right\rangle\right)\left[\right.$ Brown, 1979] the $\sigma_{\mathrm{Ku}}$ values were converted from logarithmic to linear units using $X_{\text {lin }}=10^{X_{d \delta} / 10}$. Scatterplots of $1 / \sigma_{\mathrm{Ku}}$ and in situ $U_{10}$ using inter-calibrated $\sigma_{\mathrm{Ku}}$ (Figure 2a) and non-calibrated $\sigma_{\mathrm{Ku}}$ (not shown) revealed that inter-calibration greatly reduced the scatter indeed, decreasing the RMSE of a power fit from 2.1 to $1.4 \mathrm{~m} / \mathrm{s}$.

\section{Results and Discussion}

\subsection{Relation Between In Situ and Satellite Altimeter Derived Wind Speed}

[19] Figure 2a shows scatterplots of $U_{10}$, in situ and altimeter-derived, as a function of $1 / \sigma_{\mathrm{Ku}}$. The relation between in situ and altimeter-derived, corrected $U_{10}$ was very close to one-on-one (Figure $2 b$ ). Thus, there is no evidence of systematic bias in the shipboard winds relative to satellite winds, though individual measurements or cruises may be afflicted by biases (for example resulting from airflow distortion [Griessbaum et al., 2010]). Significantly different regressions over the individual surveys were not demonstrated, except for PHASE1, where no correlation was found, and for Knorr 06 which only provided two matching data points (Table $\overline{2}$ ). Winds observed by satellites are "neutral winds" [May and Bourassa, 2011]. It was therefore probable that the UH field values of wind speed matched the altimeter wind speeds closer than those of the UCI. Figure $2 \mathrm{~b}$ of a plot of altimeter wind speed versus in situ wind speed did not show clear evidence of a difference between UH (open symbols) and UCI (closed symbols). Analysis of variance (ANOVA) using Matlab function "anova1.m," applied to the fit residuals of a linear fit between in situ and altimeter $U_{10}$ (solid line in Figure 2b), returned $P=0.65$ for the null hypothesis that the means of the groups were equal and implied that the shape of the relation between in situ and altimeter derived $U_{10}$ was the same for UH and UCI. A methodological bias between the two $U_{10}$ data sets was therefore not demonstrated. However, 

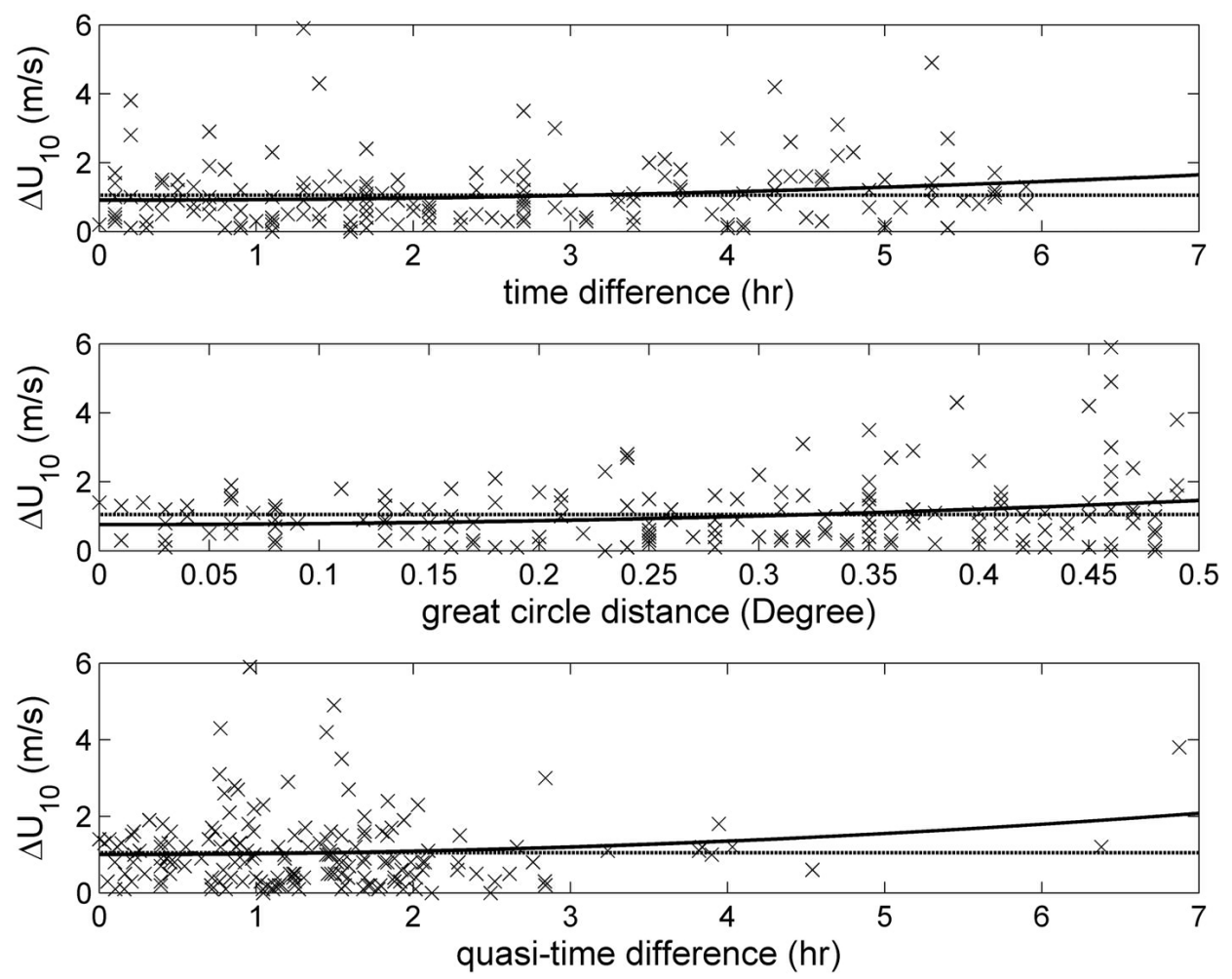

Figure 3. Scatterplots of the absolute error between corrected, altimeter derived wind speed, and in situ wind speed, $\Delta \mathrm{U}_{10}$, as a function of the absolute error between sample station and corresponding satellite pass regarding (top) time difference, fit $\mathrm{y}=0.015 \mathrm{x}^{2}+0.91\left(\mathrm{R}^{2}=0.026\right)$, (middle) distance, fit $\mathrm{y}=2.79 \mathrm{x}^{2}+$ $0.76\left(\mathrm{R}^{2}=0.049\right)$, and (bottom) quasi-time difference, fit $\mathrm{y}=0.022 \mathrm{x}^{2}+1.0\left(\mathrm{R}^{2}=0.016\right)$. The solid lines represent the nonlinear curve fits of the data, and the dotted line the mean of $\Delta \mathrm{U}_{10}$ over all data.

the same statistical test applied to the absolute values of the fit residuals returned $P=0.02$ which indicated a significant difference in their means, proving reduced scatter for $\mathrm{UH}$ data. The RMSE of the fits were 1.3 and $1.7 \mathrm{~m} / \mathrm{s}$ for $\mathrm{UH}$ and UCI data respectively.

[20] The difference between all 179 altimeter and in situ $U_{10}$ data was quantified by a mean absolute error, MAE, of $1 \mathrm{~m} / \mathrm{s}$ and a root mean square of the error, RMSE, of $1.4 \mathrm{~m} / \mathrm{s}$. For each data pair, the absolute difference between in situ and altimeter-derived wind speed, $\left|\Delta U_{10}\right|$, was plotted in Figure 3 as a function of the related deviation in time, $\Delta t(\mathrm{hr})$, great circle distance, $\Delta x$ (degree), and a combination of the two defined by quasi-time difference $(\Delta q)$. The latter was calculated following May and Bourassa [2011] using $\Delta q=$ $\sqrt{\Delta x_{c o n}^{2}+\Delta t^{2}}$, where $\Delta x_{\text {con }}$ is spatial difference converted to temporal difference, defined by $\Delta x_{\text {con }}=\left|\Delta x^{\prime}\right| /\left|U_{\text {sat }}\right|$, with $\Delta x^{\prime}$ the distance in meter and $U_{\text {sat }}$ altimeter corrected $U_{10}$. The choice of criteria for collocations of altimeter and wind speed is a necessary compromise between maximizing the number of matches, and minimizing the discrepancy due to separation. The plots show only a weak decrease in $\left|\Delta U_{10}\right|$ with decreasing space or time difference, implying that the applied matching criteria were appropriate. The coefficient of variation, $\mathrm{CV}$, defined as the RMSE normalized to the mean of the observed values, was 0.18 for the 179 data points, and 0.14 for 27 closer matches where $\mathrm{d} t<1 \mathrm{~h}$, and $\mathrm{d} x<0.2^{\circ}$.
Also, we infer that correlations between altimeter wind speed or backscatter and a matched ship-measured parameter strongly related to the wind (e.g., transfer velocity) may only be slightly degraded by the separation.

\subsection{Air-Sea Gas Transfer Coefficient of DMS as a Function of Ku-Band Backscattering}

[21] We examined the EC measurements of $K_{\mathrm{w}}, 660$ in relationship to the altimeter-derived $1 / \sigma_{\mathrm{Ku}}$ using calibrated $\sigma_{\mathrm{Ku}}\left(\right.$ Figure $4 \mathrm{a}$ ) and non-calibrated $\sigma_{\mathrm{Ku}}$ (Figure 4b). $K_{\mathrm{w}}, 660$ increased with $1 / \sigma_{\mathrm{Ku}}$, as expected, and using calibrated $\sigma_{\mathrm{Ku}}$ data significantly reduced the scatter in the relationship. For the calibrated altimeter data, linear regression over the 179 matching data pairs resulted in

$$
K_{w, 660}=\frac{2.9 \times 10^{2}}{\sigma_{K u}}-10
$$

$\left(R^{2}=0.50\right.$, RMSE $\left.=5.0\right)$, while using non-calibrated altimeter data gave poorer linear regression results $\left(R^{2}=\right.$ 0.29 , RMSE $=6.0$ ). Looking at Figure $4 \mathrm{a}$, it is possible to infer that the extreme So-GasEx data dragged down the regression slope. However, this was not proven by a linear regression over the data excluding So-GasEx. Fangohr and Woolf [2007] suggest respective values for slope and intercept of 194 and 1.3, and hence the field based relation (7) had a steeper slope than the laboratory based relation. 
(a)

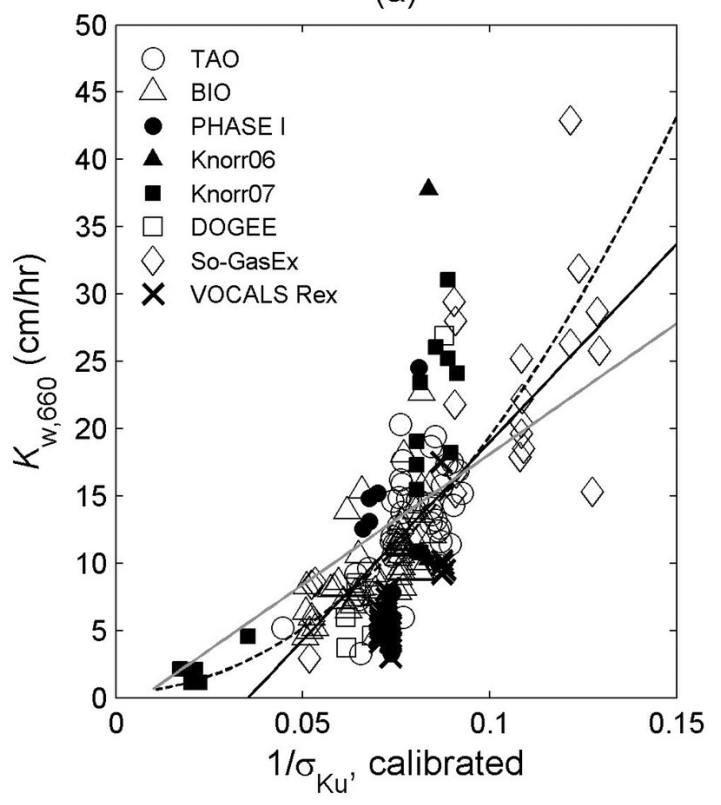

(b)

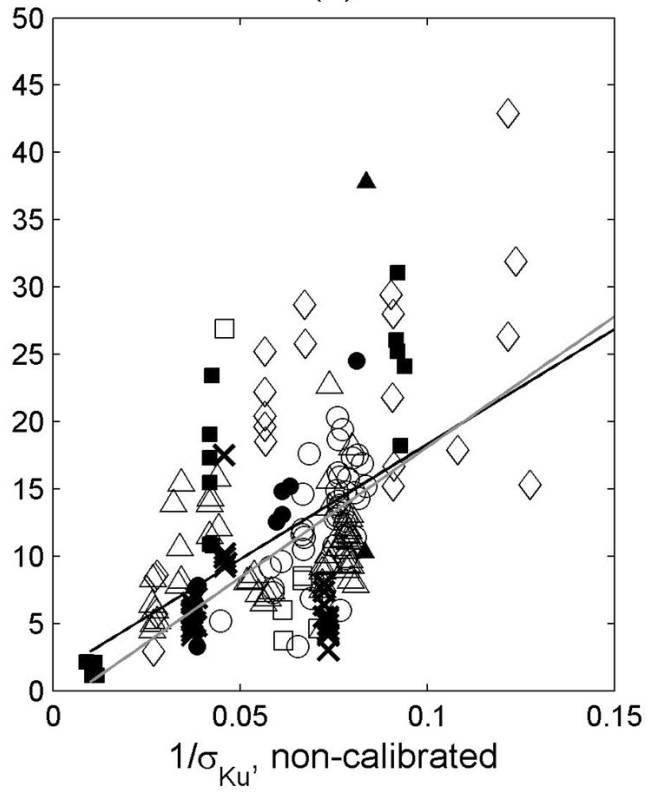

Figure 4. Scatterplots of measurements of $K_{w, 660}$ against $1 / \sigma_{K u}$ (linear) from coinciding altimeter data. (a) Using calibrated $\sigma_{\mathrm{Ku}}$; solid black line indicates linear regression (7), dotted black line indicates quadratic regression (8), and solid gray line is relation predicted by Fangohr and Woolf [2007], $\mathrm{K}_{\mathrm{w}, 660}=$ $1.9 \times 10^{2} / \sigma_{\mathrm{Ku}}+1$. (b) Using non-calibrated $\sigma_{\mathrm{Ku}}$; solid black line indicates linear regression, $\mathrm{K}_{\mathrm{w}, 660}=$ $1.7 \times 10^{2} / \sigma_{\mathrm{Ku}}+1\left(\mathrm{R}^{2}=0.29, \mathrm{RMSE}=6.0\right)$, and solid gray line is as in Figure $4 \mathrm{a}$.

Figure $4 \mathrm{a}$ shows that (7) under estimated $K_{\mathrm{w}}, 660$ for small $1 / \sigma_{\mathrm{Ku}}$ values, whereas using the square of $1 / \sigma_{\mathrm{Ku}}$,

$$
K_{w, 660}=1.9 \times 10^{3}\left(\frac{1}{\sigma_{K u}}\right)^{2}+0.4
$$

$\left(R^{2}=0.52\right.$, RMSE $\left.=5.0\right)$, gave better results. We note that while we used the signal of waves of wave number $<100 \mathrm{rad} / \mathrm{m}$, a relation of the form $a x^{2}+b$ agrees with the Frew et al. [2004] estimate of the $k-\left\langle s^{2}\right\rangle$ relationship for the wave number range $40-100 \mathrm{rad} / \mathrm{m}$. As illustrated in Figure 5a, bin-averaging all calibrated altimeter data over $1 / \sigma_{\mathrm{Ku}}$ intervals of 0.01 reinforced the parabolic relation, $K_{w, 660}=1.7 \times 10^{3} /\left(\sigma_{\mathrm{Ku}}\right)^{2}+1\left(R^{2}=0.97, \mathrm{RMSE}=1.7\right)$. By binaveraging the data statistical sampling uncertainty is reduced, a trade-off of resolution versus error. Also, information about parameters other than sea surface roughness that control gas exchange may be lost. It can be seen in Table 3 that the cruise specific linear regression slopes varied widely, and that using $\left(1 / \sigma_{\mathrm{Ku}}\right)^{2}$ instead of $1 / \sigma_{\mathrm{Ku}}$ generally gave slightly better fits. For the ten PHASE1 data points the correlation between $K_{\mathrm{w}, 660}$ and calibrated $1 / \sigma_{\mathrm{Ku}}$ was not significant (Table 3 ). Interestingly, using non-calibrated $\sigma_{\mathrm{Ku}}$ data instead gave the highly significant relation $K_{w, 660}=3.52 \times 10^{3} /\left(\sigma_{\mathrm{Ku}}\right)^{2}+1\left(R^{2}=0.95, \mathrm{RMSE}=\right.$ $\left.1.4, P<10^{-5}\right)$. The extremely large slopes and negative intercepts calculated for DOGEE data were ambiguous because only six matching data points were available. Looking at the cruises for which ten or more match-ups were found, the linear regression slopes varied $\pm 23 \%$ and $\pm 33 \%$, using $1 / \sigma_{\mathrm{Ku}}$ and $\left(1 / \sigma_{\mathrm{Ku}}\right)^{2}$ respectively. This variation was comparable to the range of slopes of about $\pm 28 \%$ of the linear relation between all measurements of $U_{10}$ and $k_{\mathrm{DMS}}$ regarding TAO, BIO,
PHASE1, and Knorr_06 [Marandino et al., 2009]. Looking at Figure $4, K_{w, 660}$ obtained during the cruises performed by UCI (solid symbols) appeared to be higher than those of the UH (open symbols). An ANOVA verified a significant difference between the two groups. (Matlab function "anova1. m" applied to the fit residuals between $K_{w, 660}$ and (8) returned a $P$ value of $2 \times 10^{-5}$ for the null hypothesis that the means of the groups are equal.) The difference could be caused by possible systematic errors due to methodological variations, such as the correction for high frequency tubing effects applied by UCI (but not by UH), and to the diverse survey locations where surfactants, SST and other environmental factors varied. For the UH measurements $K_{\mathrm{w}}, 660=$ $1.8 \times 10^{3}\left(1 / \sigma_{\mathrm{Ku}}\right)^{2}+0.2$, while for UCI, $K_{\mathrm{w}}, 660=2.9 \times$ $10^{3}\left(1 / \sigma_{\mathrm{Ku}}\right)^{2}-1$ was retrieved.

[22] We found some indication of a temperature trend, higher $K_{\mathrm{w}}, 660$ values for rising temperature, if we looked at the UH data excluding SO-GasEx data (in addition to higher winds and lower SST, SO-GasEx is distinct from the other $\mathrm{UH}$ cruises by more frequent occurrences of stable boundary layer conditions; in a more stable boundary layer, greater uncertainty and a negative bias in $K_{\mathrm{w}}, 660$ are apparent [Yang et al., 2011].) A similar trend was not seen using the UCI or combined data, and hence more measurements under a wide range of conditions will be needed in order to validate the trend.

[23] For assessment of diurnal effects in the DMS gas fluxes, we roughly approximated the true solar time of each station by estimating the time offset by a multiplication of longitude and 24/360. The result was found to be within 20 min of the true solar time, computed using a solar calculations spreadsheet of the National Oceanic \& 
(a)

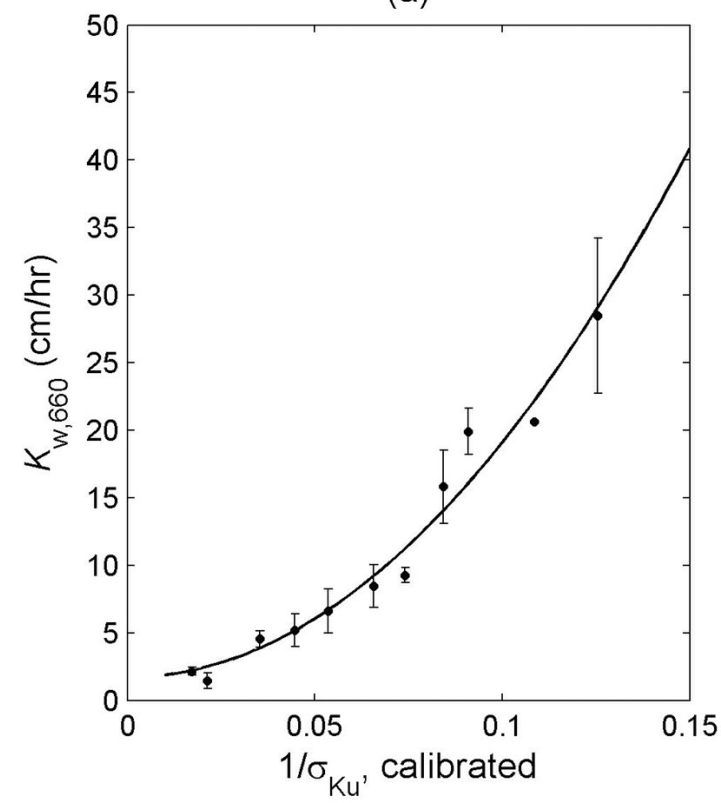

(b)

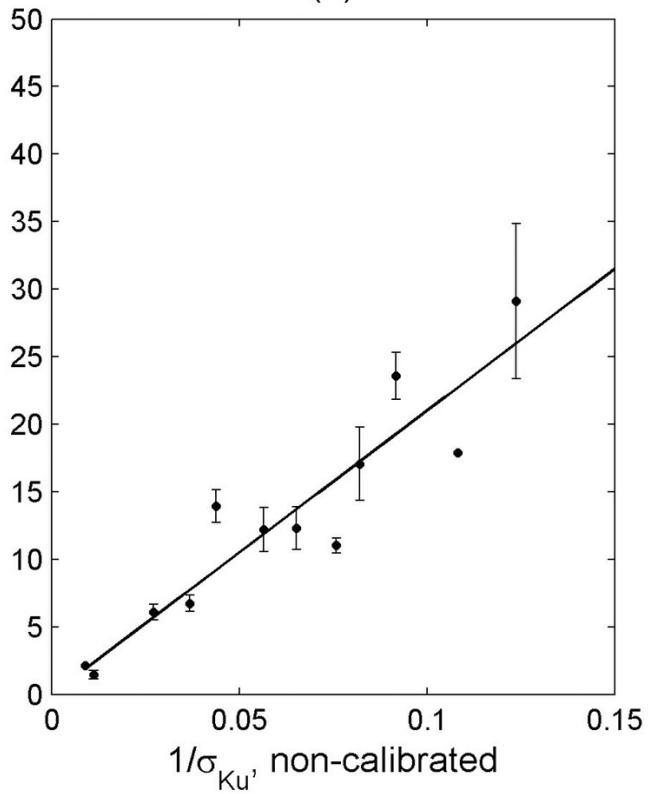

Figure 5. Same as Figure 4, except data have been binned in 0.01 intervals of $1 / \sigma_{\mathrm{Ku}}$. The vertical error bars indicate the standard error of the mean $\mathrm{K}_{\mathrm{w}, 660}$ values; for dots without an error bar only one data point was present in the interval. Curve fitting over the binned data resulted in (a) $\mathrm{K}_{\mathrm{w}, 660}=1.7 \times 10^{3} /\left(\sigma_{\mathrm{Ku}}\right)^{2}+1$ $\left(\mathrm{R}^{2}=0.97, \mathrm{RMSE}=1.7\right)$, and (b) $\mathrm{K}_{\mathrm{w}, 660}=2.1 \times 10^{2} / \sigma_{\mathrm{Ku}}\left(\mathrm{R}^{2}=0.86, \mathrm{RMSE}=3.0\right)$.

Atmospheric Administration, NOAA, (http://www.esrl. noaa.gov $/ \mathrm{gmd} / \mathrm{grad} /$ solcalc/calcdetails.html). The UH and UCI data were assessed both individually and grouped together, but no relation between $K_{\mathrm{w}}, 660$ and true solar time was found, supporting previous findings that diurnal variability in $K_{\mathrm{w}}, 660$ was not evident [Huebert et al., 2004; Marandino et al., 2009].

[24] We examined if an upgrade of the altimeter retracker algorithm in October 2005 improved $K_{\mathrm{w}}, 660$ estimation by looking at the non-calibrated $\sigma_{\mathrm{Ku}}$ values of the match-ups for Jason-1 before (MLE-3) and after (MLE-4). Only UH data were included to avoid uncertainties introduced by the discrepancies between UH and UCI data. We found 17 matches for MLE-3 and 30 for MLE-4. The regression slopes of linear fits between $\left(1 / \sigma_{\mathrm{Ku}}\right)^{2}$ and $K_{\mathrm{w}}, 660$ were significantly different for MLE-3 and MLE-4 (this did not necessarily mean a bias between the altimeter data as a similar offset was found using in situ $U_{10}$ data). We therefore performed separate regressions over MLE-3 and MLE-4 data and an ANOVA of their fit residuals derived that the means of the groups were equal $(P=1)$. Thus we could not prove that using the MLE-4, instead of the MLE-3, retracker enhanced

Table 3. Linear Regression Results of Fits Between Field Measurements of $K_{\mathrm{w}, 660}$ and $1 / \sigma_{\mathrm{Ku}}$ and $\left(1 / \sigma_{\mathrm{Ku}}\right)^{2}$ and of Fits Between Estimations of $k_{\mathrm{w}, 660}$, Using Measurements of $K_{\mathrm{w}, 660}$ and (6), and $1 / \sigma_{\mathrm{Ku}}$ and $\left(1 / \sigma_{\mathrm{Ku}}\right)^{2}$, With Inter-calibrated Altimeter Derived $\sigma_{\mathrm{Ku}}$ Values in Linear Units $^{\mathrm{a}}$

\begin{tabular}{|c|c|c|c|c|c|c|c|c|c|}
\hline & Linear Fit Results & TAO & $\mathrm{BIO}$ & PHASE1 & Knorr 07 & DOGEE & SO GasEx & Vocals Rex & All \\
\hline$K_{w, 660}$ & $a$ & 2.5 & 2.2 & NA & 3.0 & 8.2 & 2.7 & 3.6 & 2.9 \\
\hline \multirow{3}{*}{$a \cdot 10^{2} / \sigma_{K u}+b$} & $b$ & -6.7 & -5.7 & NA & -5.1 & -46 & -6.2 & -20 & -10.4 \\
\hline & $R^{2}$ & 0.37 & 0.41 & $\sim 0$ & 0.78 & 0.89 & 0.56 & 0.57 & 0.50 \\
\hline & RMSE & 3.2 & 2.7 & NA & 4.8 & 3.2 & 6.5 & 1.8 & 5.0 \\
\hline$K_{w, 660}$ & $a$ & 1.7 & 1.7 & NA & 2.8 & 5.5 & 1.5 & 2.2 & 1.9 \\
\hline \multirow{3}{*}{$a \cdot 10^{3}\left(1 / \sigma_{\mathrm{Ku}}\right)^{2}+b$} & $b$ & 2.6 & 1.7 & NA & 0.1 & -16 & 5.4 & -6.1 & 0.4 \\
\hline & $R^{2}$ & 0.36 & 0.42 & $\sim 0$ & 0.82 & 0.91 & 0.52 & 0.58 & 0.52 \\
\hline & RMSE & 3.2 & 2.7 & NA & 4.5 & 3.0 & 6.8 & 1.8 & 5.0 \\
\hline$k_{w, 660}$ & $a$ & 2.6 & 2.3 & NA & 3.3 & 9.0 & 2.9 & 3.8 & 3.2 \\
\hline \multirow{3}{*}{$a \cdot 10^{2} / \sigma_{K u}+b$} & $b$ & -7.0 & -6.0 & NA & -5.8 & -51 & -6.7 & -22 & -11.5 \\
\hline & $R^{2}$ & 0.35 & 0.40 & $\sim 0$ & 0.77 & 0.90 & 0.54 & 0.57 & 0.49 \\
\hline & RMSE & 3.5 & 2.9 & NA & 5.6 & 3.4 & 7.2 & 2.0 & 5.6 \\
\hline$k_{w, 660}$ & $a$ & 1.7 & 1.7 & NA & 3.1 & 6.0 & 1.6 & 2.4 & 2.1 \\
\hline \multirow{3}{*}{$a \cdot 10^{3}\left(1 / \sigma_{\mathrm{Ku}}\right)^{2}+b$} & $b$ & 2.8 & 1.7 & NA & -0.1 & -18 & 5.8 & -6.7 & 0.1 \\
\hline & $R^{2}$ & 0.37 & 0.40 & $\sim 0$ & 0.79 & 0.91 & 0.51 & 0.57 & 0.51 \\
\hline & RMSE & 3.5 & 2.9 & NA & 5.3 & 3.2 & 7.5 & 2.0 & 5.5 \\
\hline
\end{tabular}

${ }^{\text {a }}$ The number of matching data points for each cruise is given in Table 2, there were too few for Knorr_06 to perform a regression. 


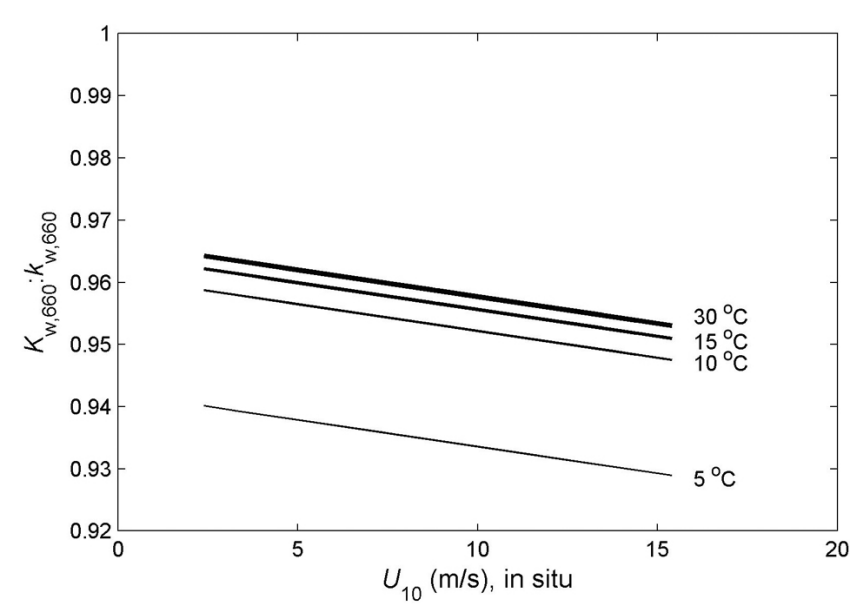

Figure 6. Ratio of observed $\mathrm{K}_{\mathrm{w}, 660}$ and calculated $\mathrm{k}_{\mathrm{w}, 660}$ (9), derived from data obtained during TAO, BIO, DOGEE, SO-GasEx and VOCALS-Rex, versus in situ $\mathrm{U}_{10}$ for a range of SST levels.

correlation between backscatter and gas transfer velocity estimations.

\subsection{Water Side Gas Transfer Velocity Coefficient of DMS}

[25] As explained in section 1.2, the $K_{\mathrm{w}}, 660$ measurements can be corrected for the air-side gas transfer velocity, $k_{\mathrm{a}}$, of DMS to retrieve $k_{\mathrm{w}}, 660$. We calculated $k_{\mathrm{a}}$ with (5), after deriving $\mathrm{Sc}_{\mathrm{a}}$ from the $T_{\text {air }}$ data. For DMS we found $\mathrm{Sc}_{\mathrm{a}}$ ranging from 1.560 to 1.568 . Estimation of $k_{\mathrm{w}, 660}$ using the $K_{\mathrm{w}, 660}, U_{10}$, salinity and SST field data, and (4)-(6), revealed that over all data $K_{\mathrm{w}}, 660$ was about 2 to $13 \%$ smaller than $k_{\mathrm{w}, 660}$. Our calculated effect of air-side resistance on air-sea gas transfer was considerably less than the $\gamma_{\mathrm{a}}$ correction $\left(\gamma_{\mathrm{a}}=1-K_{\mathrm{w}, 660} / k_{\mathrm{w}, 660}\right)$ for the high end of the wind speed range as predicted by McGillis et al. [2000]. They used a parameterization for insoluble gas, $k_{w, 660} \propto U_{10}^{2}$ [Wanninkhof, 1992], to estimate water side gas transfer. Applying their method to our data, we found $\gamma_{\mathrm{a}}$ increasing from $8 \%$ to $16 \%$ as $U_{10}$ increased from 10 to $16 \mathrm{~m} / \mathrm{s}$, whereas our $\gamma_{\mathrm{a}}$ estimation varied around $7 \pm 2 \%$. Yang et al. [2011] calculated $k_{\mathrm{a}}$ for SOGasEx data following McGillis et al. [2000] but with $k_{\mathrm{w}}$ a priori using the formulation from the NOAA COARE gas transfer model and derived a $\sim 4 \%$ underestimation of $k_{\mathrm{w}, 660}$; we derived $\sim 7 \pm 1.5 \%$ for SO-GasEx. Hence, both our work and Yang et al. [2011] showed a marked decrease of $\gamma_{\mathrm{a}}$ compared to the prediction of McGillis et al. [2000] for wind speeds $>\sim 10 \mathrm{~m} / \mathrm{s}$.

[26] In practice, regression results between $1 / \sigma_{\mathrm{Ku}}$ and $k_{\mathrm{w}, 660}$ show some very small differences compared to those between $1 / \sigma_{\mathrm{Ku}}$ and $K_{\mathrm{w}, 660}$ (Table 3 ). Nonlinear curve fitting [da Silva and da Silva, 2010] of the $K_{\mathrm{w}}, 660: k_{\mathrm{w}, 660}$ ratio as a function of $U_{10}$ and SST agreed with the finding by McGillis et al. [2000] that the underestimation of $k_{\mathrm{w}, 660}$ by $K_{\mathrm{w}, 660}$ depended on both parameters. Looking at the UH data only, so as to reduce scatter in $K_{\mathrm{w}}$ retrieval, the calculated error increased with increasing $U_{10}$ and decreasing SST $\left(5^{\circ} \mathrm{C}<\mathrm{SST}<30^{\circ} \mathrm{C}\right)$

$$
K_{w, 660}=k_{w, 660}\left(A-B \cdot U_{10}-\frac{C}{S S T^{2}}\right)
$$

$\left(R^{2}=0.44, P<1 \times 10^{-7}\right)$ where $A=0.967$ (0.003), $B=0.9 \times$ $10^{-3}\left(0.5 \times 10^{-3}\right)$ and $C=0.6(0.08)$ (standard deviation in parenthesis). A decreasing temperature lead to an increasing air-side correction (9), which can be explained by a rising gas solubility in water [McGillis et al., 2000]. The air-side correction also increased with increasing wind speed (9); according to McGillis et al. [2000] this is because $k_{\mathrm{w}}$ increases faster with increasing wind speed than $k_{\mathrm{a}}$. Our wind speed dependence is much weaker than found by McGillis et al. [2000], however, which could be explained by their application of a quadratic form of the $k_{\mathrm{w}}$ wind speed parameterization, whereas we used a linear dependence of $k_{\mathrm{w}}$ on wind speed. A plot of ratio $K_{\mathrm{w}, 660}: k_{\mathrm{w}, 660}$, calculated using (9), versus $U_{10}$ for a range of SST levels in Figure 6, shows that the magnitude of the correction at the high end of the $U_{10}$ range was about half of the one suggested by McGillis et al. [2000]. Unlike the McGillis et al. [2000] prediction, $K_{\mathrm{w}, 660}$ was not expected to equal $k_{\mathrm{w}, 660}$ at zero wind speed, but to vary from $94 \%$ to $97 \%$ of $k_{\mathrm{w}}, 660$ for SST ranging from $5^{\circ}$ to $30^{\circ} \mathrm{C}$.

[27] We estimated the variation in $K_{\mathrm{w}, 660}$ due to the SST dependence of air side resistance by differentiating (9) with respect to SST. The resulting percentage change, $\Delta K_{\mathrm{w}}, 660 /$ $K_{\mathrm{w}, 660}$, decreased rapidly with increasing SST, being $\sim 1 \% \Delta$ $\mathrm{SST}$ at $5^{\circ} \mathrm{C}, \sim 0.1 \% \Delta \mathrm{SST}$ at $10^{\circ} \mathrm{C}$, and practically zero at $15^{\circ} \mathrm{C}$ and higher SST values. This estimation implied that this effect was too small to be detected by the observations, as the $K_{\mathrm{w}, 660}$ measurement error was at least $15 \%$.

\subsection{Gas Transfer Coefficient of DMS as a Function of Wind Speed}

[28] Because gas transfer is dominated by wind-forcing, $K_{\mathrm{w}}$ is traditionally related to surface wind speed. The wind speed-only dependence for gas transfer has been described by: three linear segments, LM86 [Liss and Merlivat, 1986], a quadratic term, W92 [Wanninkhof, 1992], the sum of a linear and a quadratic term, N00 [Nightingale et al., 2000], and a cubic term WG92 [Wanninkhof and McGillis, 1999]. Wanninkhof et al. [2009] have reconciled the different approaches, and developed a third order polynomial function, W09, that can be well approximated by a conventional quadratic function for winds $<15 \mathrm{~m} / \mathrm{s}$. The origin of these "common" parameterizations is varied, but they are all based on observations of relatively insoluble gases. The relation between $K_{\mathrm{w}}, 660$, derived from the measured DMS gas fluxes, and $U_{10}$ was practically linear, and hence differed substantially from the existing parameterizations (Figure 7b).

[29] Regression of $K_{\mathrm{w}}, 660$ data, derived from the observed DMS gas fluxes, against the altimeter-derived $U_{10}$ data, plotted in Figure 7a, revealed a linear fit,

$$
K_{w, 660}=2.1 U_{10}-2.8
$$

$\left(R^{2}=0.53\right.$, RMSE $\left.=4.9\right)$. The linearity of $(10)$ can be explained by a simple physical model of wind-driven stirring for $U_{10} \sim 4-12 \mathrm{~m} / \mathrm{s}$ for DMS [Huebert et al., 2010]; for lower and higher wind speeds, the physical regime is different, and the relation may have different curvature. Intercepts of fits between $U_{10}$ and $K_{\mathrm{w}, 660}$ should not be set to zero, assuming $K_{\mathrm{w}, 660}$ is zero when wind and stress are zero, because buoyancy (rather than stress) dominates gas exchange physics in near-zero winds [Huebert et al., 2010]. For the data binned in $1 \mathrm{~m} / \mathrm{s} U_{10}$ intervals strong linear relations were obvious 
(a)

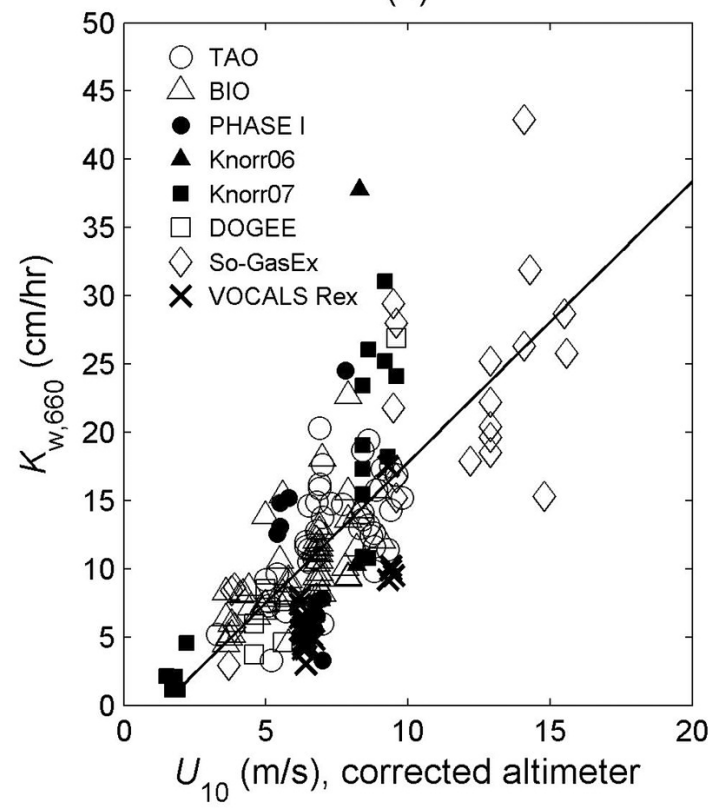

(b)

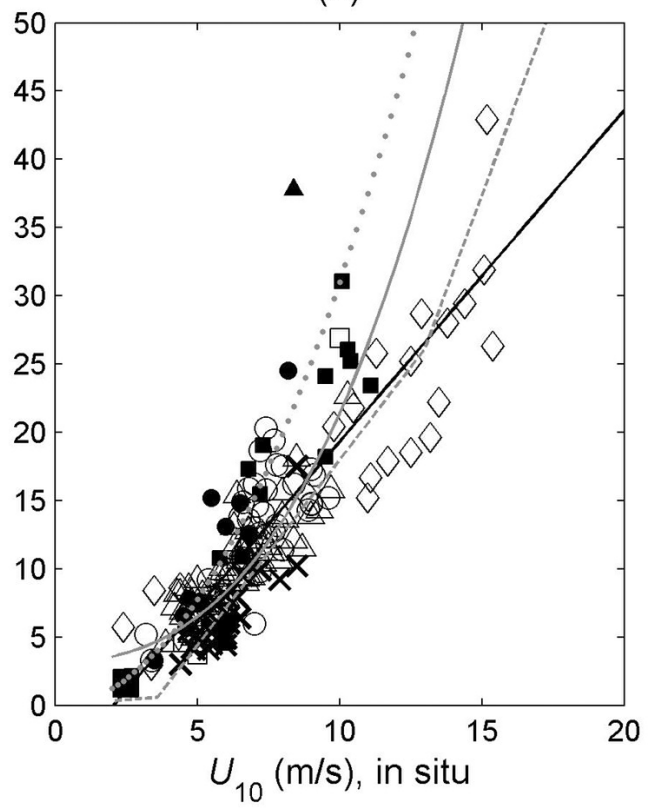

Figure 7. Scatterplots of measurements of $K_{w, 660}$ against $U_{10}$ for coinciding altimeter data. (a) Using $\mathrm{U}_{10}$, estimated from corrected altimeter data; solid black line indicates linear regression (10). (b) Using in situ $\mathrm{U}_{10}$; solid black line indicates linear regression, $\mathrm{K}_{\mathrm{w}, 660}=2.4 \mathrm{U}_{10}-5\left(\mathrm{R}^{2}=0.73\right.$, $\left.\mathrm{RMSE}=3.7\right)$, solid gray line shows W09 [Wanninkhof et al., 2009], dotted gray line W92 [Wanninkhof, 1992] and dashed gray line LM86 [Liss and Merlivat, 1986].

(Figure 8). Using corrected altimeter and in situ wind speed, linear regressions over the binned data gave respectively $K_{\mathrm{w}, 660}=1.8 U_{10}\left(R^{2}=0.97, \mathrm{RMSE}=1.7\right)$ and $K_{\mathrm{w}, 660}=$ $2.3 U_{10^{-}}\left(R^{2}=0.96, \mathrm{RMSE}=1.9\right)$. Note that for the binned data, using altimeter derived wind speeds was slightly better than using field values. In Table 4, cruise specific linear regression results for $U_{10}$ and $K_{\mathrm{w}, 660}$, and for $U_{10}$ and $k_{\mathrm{w}, 660}$, are presented. A comparison shows that for all cruises, the slope was slightly steeper for $k_{\mathrm{w}, 660}$ than for $K_{\mathrm{w}, 660}$, which was consistent with the expectation that the underestimation of $k_{\mathrm{w}, 660}$ increased with increasing $U_{10}$ (Figure 6). In the plots of $K_{\mathrm{w}, 660}$ versus $U_{10}$ (Figure 7 ), $K_{\mathrm{w}, 660}$ values of UCI appeared to be higher than those of UH. We examined this as described by analogy to the assessment of a similar increase in the $K_{\mathrm{w}, 660}$ versus $1 / \sigma_{\mathrm{Ku}}$ data (Section 3.2). It was found that the difference between the two groups was significant for in situ $U_{10}\left(P=2 \times 10^{-7}\right)$ and that using altimeter $U_{10}$ instead did not make the difference insignificant $(P=2 \times$ $10^{-4}$ ). This was not surprising as a methodological bias between UH and UCI in situ $U_{10}$ measurements was not proven (Section 3.1). Therefore, the dissimilarity between UH and UCI observations had to be rooted in other systematic differences in methodology or conditions during present the cruises.

\subsubsection{Bubble-Mediated Gas Transfer}

[30] A linear fit between $U_{10}$ and $K_{\mathrm{w}, 660}$, or a much flatter power curve than the common parameterizations, is in agreement with previous findings for DMS [Marandino et al., 2009; Blomquist et al., 2006; Huebert et al., 2010]. The difference with the common gas transfer parameterizations, could be explained by gas transfer due to bubbles for the relatively insoluble gases, as $K_{\mathrm{b}}$ is understood to be proportional to fractional whitecap coverage, $W$, [Woolf, 2005], and $W$ roughly scales to $U_{10}^{3}$ [Goddijn-Murphy et al., 2011]. However, simultaneous $K_{\mathrm{w}, 660}$ measurements of DMS and $\mathrm{CO}_{2}$ during Knorr_07 both showed a fairly linear dependence on wind speed, implying that solubility was not an important factor for wind speeds $<10 \mathrm{~m} / \mathrm{s}$ [Miller et al., 2009]. Applying the altimeter corrected wind speeds in (10), gave as good a result as applying the altimeter calibrated backscatter in (8). This is not surprising since the retrieved wind speed is based on backscatter values, and the backscatter signal is tuned using buoy and ECMWF wind speed data.

\subsubsection{Errors Related to Wind Speed}

[31] We consider first only those measurement errors which are random and unbiased. It was expected that variations in wind speed resulted in variations in $K_{\mathrm{w}, 660}$. The standard deviation in $U_{10}$ of $\sim 1 \mathrm{~m} / \mathrm{s}$ of the UCI data accounted for its genuine variation as well as for random wind speed measurement errors, so the standard deviation about the 'true wind' speed was presumably smaller and the standard error of the hourly mean will yet be smaller. The propagation of a small error in $x, \Delta x$, in a function $f(x)$ can be approximated using $\Delta f(x)=(\delta f / \delta \mathrm{x}) \Delta \mathrm{x}$ [Taylor, 1997]. Applying this to (10), the propagation of an error in $U_{10}$ of $\sim 1 \mathrm{~m} / \mathrm{s}(\sim 15 \%)$ was estimated to be $\sim 2 \mathrm{~cm} / \mathrm{hr}(\sim 15 \%)$, which would explain only part of the $25 \%$ standard deviation in $K_{\mathrm{w}}, 660$ for the UCI data. Thus simple random errors in wind speed are unlikely to contribute greatly to errors in the relationship with transfer velocity. Data scatter in $K_{\mathrm{w}, 660}$ versus $U_{10}$ is reduced when wind speeds are normalized to neutral wind speed [Yang et al., 2011]. Although the RMSE of a linear fit over the UH in situ data was smaller than over 
(a)

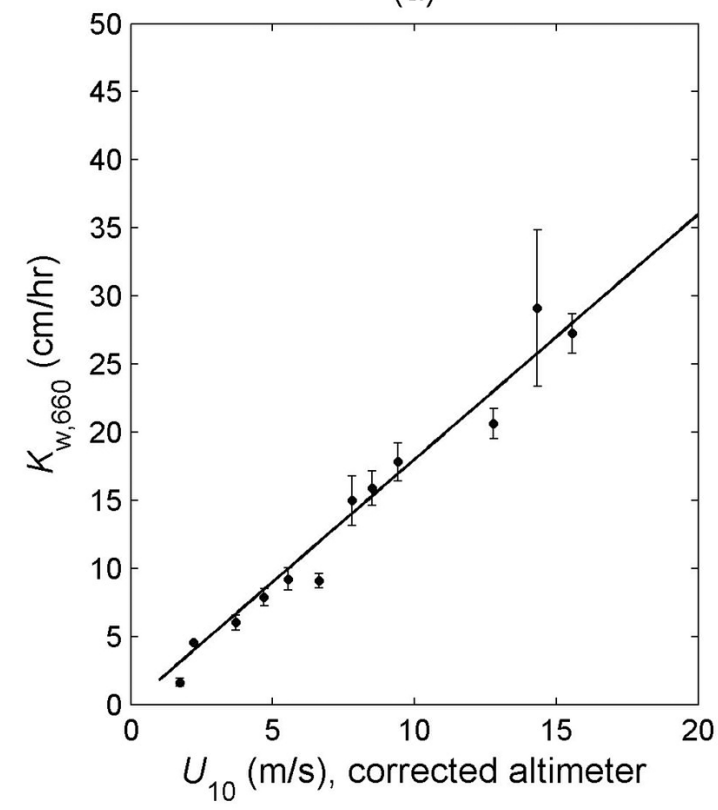

(b)

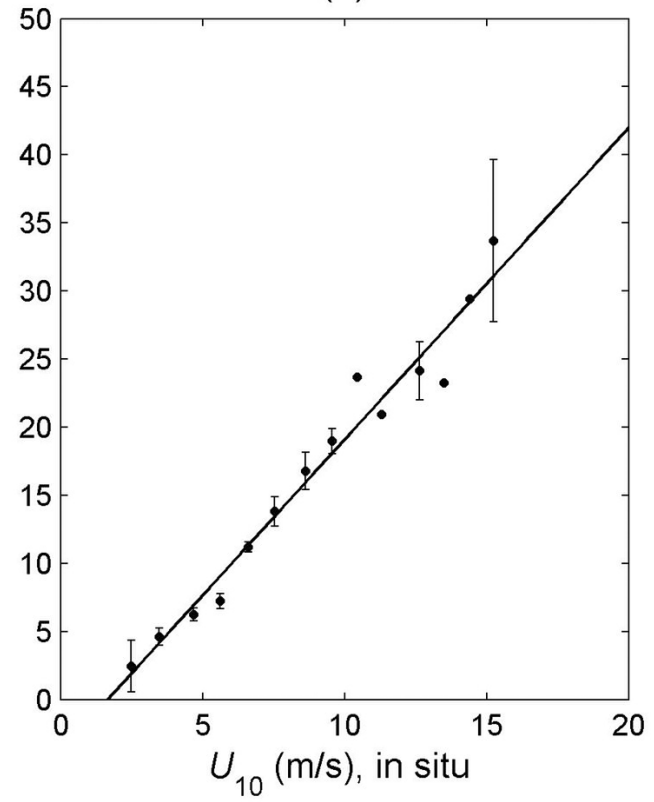

Figure 8. Same as Figure 7, except data have been binned in $1 \mathrm{~m} / \mathrm{s}$ intervals of $U_{10}$. The vertical error bars indicate the standard error of the mean $\mathrm{K}_{\mathrm{w}, 660}$ values; for dots without an error bar only one data point was present in the interval. Linear regression over the binned data resulted in (a) $\mathrm{K}_{\mathrm{w}, 660}=1.8 \mathrm{U}_{10}\left(\mathrm{R}^{2}=\right.$ 0.97 , RMSE $=1.7)$, and (b) $\mathrm{K}_{\mathrm{w}, 660}=2.3 \mathrm{U}_{10^{-4}}\left(\mathrm{R}^{2}=0.96\right.$, $\left.\mathrm{RMSE}=1.9\right)$.

the UCI in situ data $(3.0$ and $4.7 \mathrm{~cm} / \mathrm{hr}$ respectively), it is unknown how much of this was a consequence of normalizing $U_{10}$ because of other differences between the two data sets (environmental as well as methodological).

[32] Systematic errors in wind speed, for example related to airflow distortion [Griessbaum et al., 2010], may contribute to errors in computed relationships between transfer velocity and shipboard wind speed. By using altimeter data we are able to avoid errors associated with shipboard winds, but the altimeter products have their own uncertainties. Neither set (UH and $\mathrm{UCI}$ ) of shipboard wind speeds exhibited a clear systematic discrepancy with altimeter wind speeds. We can infer, therefore, that differences between the treatment of wind speeds by UH and UCI cannot explain differences in the transfer velocity - wind speed relationship. Using altimeter data enables the construction of global climatologies of transfer velocity or gas flux in a consistent way based on a homogenous product. However, there is also no evidence that simply applying observed relationships between shipboard winds and transfer velocities through any suitable global wind speed product will produce a less accurate climatology. The biggest obstacle to more accurate

Table 4. Linear Regression Results of Fits Between Field Measurements of $K_{\mathrm{w}, 660}$ and Corrected Altimeter and In Situ Wind Speed, Respectively $U_{10, \mathrm{a}}$ and $U_{10, \text { is }}(\mathrm{m} / \mathrm{s})$, and of Fits Between Estimations of $k_{\mathrm{w}, 660}$, Using Measurements of $K_{\mathrm{w}, 660}$ and (6), and $U_{10, \mathrm{a}}$ and $U_{10, \text { is }}(\mathrm{m} / \mathrm{s})^{\mathrm{a}}$

\begin{tabular}{|c|c|c|c|c|c|c|c|c|c|}
\hline & Linear Fit Results & TAO & $\mathrm{BIO}$ & PHASE1 & Knorr 07 & DOGEE & SO GasEx & Vocals Rex & All \\
\hline$K_{w}, 660$ & $a$ & 1.6 & 1.5 & NA & 2.6 & 4.3 & 1.7 & 1.8 & 2.1 \\
\hline \multirow[t]{3}{*}{$a \cdot U_{10, \mathrm{a}}+b$} & $b$ & 1.6 & 0.9 & NA & -2.9 & -15 & 1.5 & -6 & -2.8 \\
\hline & $R^{2}$ & 0.36 & 0.43 & $\sim 0$ & 0.77 & 0.92 & 0.54 & 0.57 & 0.53 \\
\hline & RMSE & 3.2 & 2.7 & NA & 5.0 & 2.7 & 6.6 & 1.8 & 4.9 \\
\hline$K_{w, 660}$ & $a$ & 2.1 & 1.9 & 4.3 & 3.1 & 4.4 & 2.1 & 2.3 & 2.4 \\
\hline \multirow{3}{*}{$a \cdot U_{10, \text { is }}+b$} & $b$ & -2.2 & -2.1 & -13 & -6.6 & -17 & -1.7 & -7.2 & -5.0 \\
\hline & $R^{2}$ & 0.51 & 0.73 & 0.88 & 0.89 & 0.98 & 0.77 & 0.71 & 0.73 \\
\hline & RMSE & 2.8 & 1.8 & 2.3 & 3.5 & 1.3 & 4.7 & 1.5 & 3.7 \\
\hline$k_{w, 660}$ & $a$ & 1.6 & 1.6 & NA & 2.9 & 4.7 & 1.9 & 2.0 & 2.2 \\
\hline \multirow{3}{*}{$a \cdot U_{10, \mathrm{a}}+b$} & $b$ & 1.7 & 0.9 & NA & -3.3 & -17 & 1.6 & -6.7 & -3.4 \\
\hline & $R^{2}$ & 0.34 & 0.42 & $\sim 0$ & 0.75 & 0.92 & 0.53 & 0.58 & 0.52 \\
\hline & RMSE & 3.5 & 2.9 & NA & 5.8 & 2.9 & 7.3 & 2.0 & 5.5 \\
\hline$k_{w, 660}$ & $a$ & 2.2 & 2.0 & 4.7 & 3.4 & 4.8 & 2.2 & 2.5 & 2.6 \\
\hline \multirow[t]{3}{*}{$a \cdot U_{10, \text { is }}+b$} & $b$ & -2.3 & -2.2 & -14 & -7.5 & -19 & -1.7 & -7.8 & -5.7 \\
\hline & $R^{2}$ & 0.49 & 0.72 & 0.87 & 0.87 & 0.98 & 0.74 & 0.70 & 0.71 \\
\hline & RMSE & 3.1 & 2.0 & 2.6 & 4.2 & 1.5 & 5.4 & 1.7 & 4.2 \\
\hline
\end{tabular}

\footnotetext{
${ }^{\mathrm{a}}$ The number of matching data points for each cruise is given in Table 2, there were too few for Knorr 06 to perform a regression.
} 
parameterizations and climatologies are unexplained discrepancies between the apparent relationship to wind speed from individual cruises and sets of cruises (UH and UCI).

\subsubsection{Measurement Errors and Undefined Environmental Dependence}

[33] Gas transfer velocity did not correlate perfectly with wind speed for a number of reasons. Factors additional to wind speed may partly control air-sea gas transfer. Various measurement errors in gas transfer velocity are also a major consideration [Asher, 2009]. For the UH data it is reported that the variation in transfer velocities reflects a combination of both measurement uncertainties and the influence of factors additional to wind speed [Huebert et al., 2004, 2010]. In this study we found no clear evidence of environmental factors additional to wind speed on transfer velocities normalized to a standard Schmidt number, though there is some suggestion that sea surface temperature may be significant. Much of the uncertainty in $K_{\mathrm{w}}, 660$ may be a consequence of statistical sampling variability, which is minimized by binaveraging the data (Figures 5 and 8).

[34] A plot of $K_{\mathrm{w}}, 660$ versus the in situ $U_{10}$ measurements over the 179 data points (Figure $7 \mathrm{~b}$ ) showed less spread in the data than using either altimeter-derived parameter (Figures 4 and 7a). The RMSE in $K_{\mathrm{w}}, 660$ as a function of in situ and altimeter wind speed was 3.7 and $4.9 \mathrm{~cm} / \mathrm{hr}$ respectively, and $5 \mathrm{~cm} / \mathrm{hr}$ as a function of altimeter backscatter (Table 4). Spatial and temporal separation between the altimeter data points and sample stations did contribute to scatter in satellite derived $K_{\mathrm{w}}, 660$. For the 179 matching data points $\mathrm{RMSE}=5.0$ and $\mathrm{CV}=42 \%$, while for 27 closer matches $\left(\mathrm{d} t<1 \mathrm{~h}, \mathrm{~d} x<0.2^{\circ}\right) \mathrm{RMSE}=3.4$ and $\mathrm{CV}=33 \%$ was found. The inter-calibration of the altimeters may also have introduced errors in $K_{\mathrm{w}}, 660$ retrievals, as it is based on minimizing errors in buoy and model $U_{10}$ (Section 2.2). This calibration would account for backscattering properties of whitecaps and swells generated by the wind. Whitecaps and swells can have an effect on gas transfer also, but not in a similar manner. For example $W \propto \mathrm{U}_{10}^{3}$ [Goddijn-Murphy et al., 2011] while $K_{\mathrm{b}} \propto W$ [Woolf, 2005] for poorly soluble gas and $K_{\mathrm{b}} \approx 0$ for DMS. Therefore the applied inter-calibration would not necessarily reduce errors in $K_{\mathrm{w}, 660}$. It is interesting in this regards, that the laboratory-derived relation between $K_{\mathrm{w}, 660}$ and $1 / \sigma_{\mathrm{Ku}}$, applied by Fangohr and Woolf [2007], was closer to our fit using non-calibrated $\sigma_{\mathrm{Ku}}$ (Figures $4 \mathrm{~b}$ and $5 \mathrm{~b}$ ), than using calibrated $\sigma_{\mathrm{Ku}}$ (Figures $4 \mathrm{a}$ and 5a). Also, applying noncalibrated $\sigma_{\mathrm{Ku}}$ gave superior results compared to calibrated $\sigma_{\mathrm{Ku}}$, and even to in situ $U_{10}$, for the PHASE1 survey. An inter-calibration between the satellite altimeters based on the minimization of errors in $K_{\mathrm{w}, 660}$ would probably improve $K_{\mathrm{w}, 660}$ estimations, but this is not a realistic proposition as there are not nearly as many field values of $K_{\mathrm{w}, 660}$ as there are of $U_{10}$.

\section{Conclusion}

[35] Ku-band backscattering coefficients from satellite altimeters could be used to assess air-sea gas transfer of DMS on a global scale. The different parameterizations (linear or power relation) based on the calibrated altimeter data approximated the gas transfer velocity data with RMSE values of typically $5 \mathrm{~cm} / \mathrm{h}$. Using wind speeds derived from
$\mathrm{Ku}$-band backscattering gave equally good results. It is questionable whether any chosen algorithm is more accurate than $5 \mathrm{~cm} / \mathrm{h}$. In general, inter-calibrating the backscatter coefficients between the different altimeters significantly improved the assessments. However, because the intercalibration involved minimizing errors of altimeter derived wind speeds with buoy and model wind speeds and was performed on large scales and over long periods, it was possible that information about gas transfer (related to small scale surface roughness) was lost. Many more gas transfer measurements are needed to enable an inter-calibration based on minimizing the errors in gas transfer velocities. P. Queffeulou (personal communication, 2011) has planned to add the C-band backscatter coefficient, available for TOPEX, and Jason-1\&2, to the IFREMER's altimeter database. It is possible that upgrading the altimeters retracker algorithm from MLE-3 to MLE-4 could improve air-sea gas estimations but we didn't find clear evidence of that. It will be interesting to see if using $\mathrm{Ku}$ minus $\mathrm{C}$ band scattering, as suggested by Frew et al. [2007, 2004] and Glover et al. [2007, 2002], will give better results than using single Ku-band scattering. To apply our results to other gases, air-side resistance and bubble-mediated gas transfer must be considered (see end of section 1.2). However, that extrapolation is beyond the scope of this paper.

[36] Acknowledgments. This research is a contribution of the National Centre for Earth Observation, a NERC Collaborative Centre. We appreciate the use of DMS concentration and flux data and the support of Barry Hubert and Byron Blomquist from the Huebert group at the University of Hawaii, and the satellite altimeter data made available by Pierre Queffeulou of the Laboratoire d'Océanographie Spatiale, IFREMER, France. This research was partly supported by the European Space Agency (ESA) Support to Science Element (STSE) project OceanFlux Greenhouse Gases (contract 4000104762/11/I-AM).

\section{References}

Abdalla, S. (2007), Ku-band radar altimeter surface wind speed algorithm, paper presented at ENVISAT Symposium 2007, Eur. Space Agency, Montreux, Switzerland, 23-27 April.

Asher, W. E. (2009), The effects of experimental uncertainty in parameterizing air-sea gas exchange using tracer experiment data, Atmos. Chem. Phys., 9, 131-139.

Blomquist, B. W., C. W. Fairall, B. J. Huebert, J. W. Kieber, and G. R. Westby (2006), DMS sea-air transfer velocity: Direct measurements by eddy covariance and parameterization based on the NOAA/COARE gas transfer model, Geophys. Res. Lett., 33, L07601, doi:10.1029/ 2006GL025735

Bock, E. J., T. Hara, N. M. Frew, and W. R. McGillis (1999), Relationship between air-sea gas transfer and short wind waves, J. Geophys. Res., 104 (C11), 25,821-25,831, doi:10.1029/1999JC900200.

Brown, G. S. (1979), Estimation of surface wind speeds using satelliteborne radar measurements at normal incidence, J. Geophys. Res., 84 (B8), 3974-3978, doi:10.1029/JB084iB08p03974.

Chapron, B., K. Katsaros, T. Elfouhaily, and D. Vandemark (1995), A note on relationships between sea surface roughness and altimeter backscatter, in Air-Water Gas Transfer, 3rd International Symposium on Air-Water Gas Transfer, edited by B. Jähne and E. C. Monahan, pp. 869-878, AEON, Germany.

Cox, C., and W. Munk (1954), Measurement of roughness of the sea surface from photographs of the sun's glitter, J. Opt. Soc. Am., 44(11), 838-850, doi:10.1364/JOSA.44.000838.

Dacey, J. W. H., S. G. Wakeham, and B. Howes (1984), Henry's law constants for dimethylsulfide in freshwater and seawater, Geophys. Res. Lett. 11(10), 991-994, doi:10.1029/GL011i010p00991.

da Silva, W. P., and C. P. da Silva (2010), LAB Fit Curve Fitting Software (Nonlinear Regression and Treatment of Data Program), V 7.2.47, Univ. Fed. de Campina Grande, Campina Grande, Brazil.

Fairall, C. W., E. F. Bradley, J. E. Hare, A. A. Grachev, and J. B. Edson (2003), Bulk parameterization of air-sea fluxes: Updates and verification 
for the COARE algorithm, J. Clim., 16, 571-591, doi:10.1175/1520-0442 (2003)016<0571:BPOASF $>2.0 . C O ; 2$.

Fairall, C. W., M. X. Yang, L. Bariteau, J. B. Edson, D. Helmig, W. R. McGillis, S. Perzoa, J. E. Hare, B. J. Huebert, and B. W. Blomquist (2011), Implementation of the Coupled Ocean-atmosphere Response Experiment flux algorithm with $\mathrm{CO}_{2}$, dimethyl sulfide, and $\mathrm{O}_{3}, J$. Geophys. Res., 116, C00F09, doi:10.1029/2010JC006884.

Fangohr, S., and D. K. Woolf (2007), Application of new parameterization of gas transfer velocity and their impact on regional and global marine $\mathrm{CO}_{2}$ budgets, J. Mar. Syst., 66, 195-203, doi:10.1016/j.jmarsys.2006.01.012.

Fangohr, S., D. K. Woolf, C. D. Jeffery, and I. S. Robinson (2008), Calculating long-term global air-sea flux of carbon dioxide using scatterometer, passive microwave and model reanalysis wind data, J. Geophys. Res., 113, C09032, doi:10.1029/2005JC003376.

Frew, N. M., et al. (2004), Air-sea gas transfer: Its dependence on wind stress, small-scale roughness, and surface films, J. Geophys. Res., 109, C08S17, doi:10.1029/2003JC002131.

Frew, N. M., D. M. Glover, E. J. Bock, and S. J. McCue (2007), A new approach to global air-sea gas transfer velocity fields using dual-frequency altimeter backscatter, J. Geophys. Res., 112, C11003, doi:10.1029/ 2006JC003819.

Glover, D. M., N. M. Frew, S. J. McCue, and E. J. Bock (2002), A multi-year time series of global gas transfer velocity from the TOPEX dual frequency, normalized backscatter algorithm, in Gas Transfer at Water Surfaces, Geophysical Monogr. Ser., vol. 127, edited by M. Donelan et al., pp. 325-331, AGU, Washington, D. C.

Glover, D. M., N. M. Frew, and S. J. McCue (2007), Air-sea gas transfer velocity estimates from the Jason-1 and TOPEX altimeters: Prospects for a long-term global time series, J. Mar. Syst., 66, 173-181, doi:10.1016/j.jmarsys.2006.03.020.

Goddijn-Murphy, L., D. K. Woolf, and A. H. Callaghan (2011), Parameterizations and algorithms for oceanic whitecap coverage, J. Phys. Oceanogr., 41(4), 742-756, doi:10.1175/2010JPO4533.1.

Gourrion, J., D. Vandemark, S. Bailey, B. Chapron, G. P. Gommenginger, P. G. Challenor, and M. A. Srokosz (2002), A two-parameter wind speed algorithm for Ku-band altimeters, J. Atmos. Oceanic Technol., 19, 2030-2048, doi:10.1175/1520-0426(2002)019<2030:ATPWSA>2.0.CO;2.

Griessbaum, F., B. I. Moat, Y. Narita, M. J. Yelland, O. Klemm, and M. Uematsu (2010), Uncertainties in wind speed dependent $\mathrm{CO}_{2}$ transfer velocities due to airflow distortion at anemometers sites on ships, Atmos Chem. Phys., 10, 5123-5133, doi:10.5194/acp-10-5123-2010.

Huebert, B. J., B. W. Blomquist, J. E. Hare, C. W. Fairall, J. E. Johnson, and T. S. Bates (2004), Measurement of the air-sea DMS flux and transfer velocity using eddy correlation, Geophys. Res. Lett., 31, L23113, doi:10.1029/2004GL021567.

Huebert, B. J., B. W. Blomquist, M. X. Yang, S. D. Archer, P. D Nightingale, M. J. Yelland, J. Stephens, R. W. Pascal, and B. I. Moate (2010), Linearity of DMS transfer coefficient with both friction velocity and wind speed in the moderate wind speed range, Geophys. Res. Lett., 37, L01605, doi:10.1029/2009GL041203.

Jähne, B., K. O. Münnich, R. Bösinger, A. Dutzi, W. Huber, and P. Libner (1987), On the parameters influencing air-water gas exchange, J. Geophys. Res., 92, 1937-1949, doi:10.1029/JC092iC02p01937.

Johnson, M. T. (2010), A numerical scheme to calculate temperature and salinity dependent air-water transfer velocities for any gas, Ocean Sci., 6, 913-932, doi:10.5194/os-6-913-2010.

Liss, P. S., and L. Merlivat (1986), Air-sea gas exchange rates: Introduction and synthesis, in The Role of Air-Sea Exchange in Geochemical Cycling, edited by P. Buat-Menard, pp. 113-127, D. Reidel, Dordrecht, Netherlands.

Marandino, C., W. de Bruyn, S. Miller, and E. S. Saltzman (2007), Eddy correlation measurements of the air/sea flux of dimethylsulfide over the North Pacific Ocean, J. Geophys. Res., 112, D03301, doi:10.1029/ 2006JD007293

Marandino, C. A., W. J. De Bruyn, S. D. Miller, and E. S. Saltzman (2008), DMS air/sea flux and gas transfer coefficients from the North Atlantic summertime coccolithophore bloom, Geophys. Res. Lett., 35, L23812, doi:10.1029/2008GL036370.

Marandino, C. A., W. J. De Bruyn, S. D. Miller, and E. S. Saltzman (2009), Open ocean DMS air/sea fluxes over the eastern South Pacific Ocean, Atmos. Chem. Phys., 9, 345-356, doi:10.5194/acp-9-345-2009.

May, J. C., and M. A. Bourassa (2011), Quantifying variance due to temporal and spatial difference between ship and satellite winds, J. Geophys. Res., 116, C08013, doi:10.1029/2010JC006931.

McGillis, W. R., J. W. H. Dacey, N. M. Frew, E. J. Bock, and R. K. Nelson (2000), Water-air flux of dimethylsulfide, J. Geophys. Res., 105(C1) 1187-1193, doi:10.1029/1999JC900243.

Miller, S., C. Marandino, W. de Bruyn, and P. Schlosser (2009), Air-sea gas exchange of $\mathrm{CO}_{2}$ and DMS in the North Atlantic by eddy covariance, Geophys. Res. Lett., 36, L15816, doi:10.1029/2009GL038907.

Nightingale, P. D. (2009), Air-sea gas exchange, in Surface Ocean-Lower Atmosphere Processes, Geophys. Monogr. Ser., vol. 187, edited by C. Le Quéré and E. S. Saltzman, pp. 69-97, AGU, Washington, D. C., doi:10.1029/2008GM000774.

Nightingale, P. D., G. Malin, C. S. Law, A. J. Watson, and P. S. Liss (2000), In situ evaluation of air-sea gas exchange parameterizations using novel conservative and volatile tracers, Global Biogeochem. Cycles, 14, 373-387, doi:10.1029/1999GB900091.

Quartly, G. D. (2009), Optimizing $\sigma^{0}$ information from the Jason-2 altimeter, IEEE Geosci. Remote Sens. Lett., 6, 398-402, doi:10.1109/ LGRS.2009.2013973

Queffeulou, P. (2004), Long-term validation of wave height measurements from altimeters, Mar. Geod., 27(3-4), 495-510, doi:10.1080/ 01490410490883478

Queffeulou, P., A. Bentamy, and D. Croizé-Fillon (2010), Analysis of seasonal wave height anomalies from satellite data over the global oceans, paper presented at ESA Living Planet Symposium, Eur. Space Agency, Bergen, Norway, 28 June to 2 July.

Taylor, J. R. (1997), An Introduction to Error Analysis, 2nd ed., 333 pp., Univ. Sci. Books, Sausalito, Calif.

Wanninkhof, R. (1992), Relationship between wind speed and gas exchange over the ocean, J. Geophys. Res., 97(C5), 7373-7382, doi:10.1029/92JC00188.

Wanninkhof, R., and W. R. McGillis (1999), A cubic relationship between air-sea $\mathrm{CO}_{2}$ exchange and wind speed, Geophys. Res. Lett., $26(13), 1889$ 1892, doi:10.1029/1999GL900363.

Wanninkhof, R., W. E. Asher, D. T. Ho, C. Sweeney, and W. R. McGillis (2009), Advances in quantifying air-sea gas exchange and environmental forcing, Аnnu. Rev. Mar. Sci., 1, 213-244, doi:10.1146/annurev. marine.010908.163742.

Witter, D. L., and D. B. Chelton (1991), A Geosat altimeter wind speed algorithm and a method for altimeter wind speed algorithm development, J. Geophys. Res., 96(C5), 8853-8860, doi:10.1029/91JC00414.

Woolf, D. K. (1993), Bubbles and the air-sea transfer velocity of gases, Atmos. Ocean, 31(4), 517-540, doi:10.1080/07055900.1993.9649484.

Woolf, D. (1997), Bubbles and their role in air-sea gas exchange, in The Sea Surface and Global Change, edited by P. S. Liss and R. A. Duce, pp. 173-206, Cambridge Univ. Press, Cambridge, U. K., doi:10.1017/ CBO9780511525025.007.

Woolf, D. K. (2005), Parametrization of gas transfer velocities and seastate-dependent wave breaking, Tellus, Ser. B, 57, 87-94.

Yang, M. X., B. W. Blomquist, and B. J. Huebert (2009), Constraining the concentration of the hydroxyl radical in a stratocumulus topped marine boundary layer from sea-to-air eddy covariance flux measurements of dimethylsulfide, Atmos. Chem. Phys., 9, 9225-9236, doi:10.5194/acp-99225-2009.

Yang, M. X., B. W. Blomquist, C. W. Fairall, S. Archer, and B. J. Huebert (2011), Air-sea exchange of dimethylsulfide in the Southern Ocean: Measurements from SO GasEx compared to temperate and tropical regions, J. Geophys. Res., 116, C00F05, doi:10.1029/2010JC006526. 